\title{
Development and characterization of wheat lines with increased levels of arabinoxylan
}

Karolina Tremmel-Bede ${ }^{1}$, László Láng ${ }^{1}$, Kitti Török ${ }^{2}$, Sándor Tömösközi ${ }^{2}$, Gyula Vida ${ }^{1}$, Peter R. Shewry ${ }^{3}$, Zoltán Bedő ${ }^{1}$, Marianna Rakszegi ${ }^{1 *}$

${ }^{1}$ Agricultural Institute, Centre for Agricultural Research, Hungarian Academy of Sciences, 2462-Martonvásár, Hungary

${ }^{2}$ Department of Applied Biotechnology and Food Science, Budapest University of Technology and Economics, 1111-Budapest, Hungary

${ }^{3}$ Department of Plant Science, Rothamsted Research, Harpenden, Hertfordshire AL52JQ, United Kingdom

*Corresponding author: rakszegi.mariann@agrar.mta.hu; ; +3622569500

\begin{abstract}
Improving the nutritional quality and health benefits of food has been of increasing interest globally over the last decade. Staple cereal foods are the major sources of dietary fiber and a recent study identified the Chinese wheat cultivar Yumai-34 as having unusually high levels of water-extractable arabinoxylan (WE-AX) and total arabinoxylan (TOT-AX) in flour. Crosses were therefore made between this variety and three Central European varieties (Lupus, Mv-Mambo, Ukrainka) and the physical properties (test weight, thousand-kernel weight, flour yield, kernel hardness), composition (protein, gluten, WEAX, total AX) and processing quality (gluten index, Zeleny sedimentation, Farinograph parameters) of the grain were compared for thirty-one breeding lines $\left(\mathrm{F}_{7}-\mathrm{F}_{9}\right)$ and the four parents in a three-year field experiment (2013-2015). Increases of $0.5 \%$ in the WE-AX content and $1 \%$ in the content of total AX content of the flour were achieved, with an improvement in dough properties. The thousand-kernel weight, protein content, gluten content, Zeleny sedimentation and water absorption of the flour also increased in many lines, while three of the lines had yields that were competitive with the official control varieties, making them suitable for registration.
\end{abstract}

Keywords Arabinoxylan, Breeding, Cereals, Dietary fiber, Triticum aestivum

\begin{abstract}
Abbreviations
A:X - Arabinose:xylose ratio, AGP - Arabinogalactan peptide, AX - Arabinoxylan, DF Dietary fiber, DH - Doubled haploid, GC - Gas chromatography, GI - Gluten index, HI Hardness index, LU - Lupus, MA - Mv-Mambo, RFLP - Restriction fragment length polymorphism, PCA - Principal component analysis, SSD - Single-seed descent, TKW Thousand-kernel weight, TOT - Total, TW - Test weight, UK - Ukrainka, YU - Yumai-34, WA - Farinograph water absorption, WE - Water-extractable, WU - Water unextractable
\end{abstract}




\section{Introduction}

Since the second half of the $20^{\text {th }}$ century the most important aim of wheat breeders has been to increase grain yield. However, during the 1970s and 1980s improvements in grain processing quality also gained in importance, while in the past 10-15 years the demand for improved nutritional quality and health benefits has also been recognised by breeders. In particular, there is increasing interest in developing new types of wheat with higher contents of beneficial components (notably dietary fiber, and micronutrients) in the endosperm and/or the whole grain.

The mature wheat (Triticum aestivum) grain consists of $75-80 \%(\mathrm{w} / \mathrm{w})$ carbohydrate, $9-14 \%$ protein, $1-2 \%$ lipids and $1.5-3 \%$ ash. Between $75 \%$ and $80 \%$ of the carbohydrate is starch, with 7\% low molecular weight carbohydrates (mono-, di- and oligosaccharides, fructans) and $12 \%$ cell-wall polysaccharides. The cell-wall polysaccharides are the major dietary fiber components, but fructans and resistant starch may also contribute. However, the grain consists of several tissues that differ in composition and can be separated, to varying extents, by milling. The major tissue is the starchy endosperm, which accounts for over $80 \%$ of the grain. It contains gluten storage proteins, but is low in non-starch polysaccharides (about 2-3\%), minerals, vitamins and phytochemicals. The starchy endosperm is surrounded by a single layer of thick-walled endosperm cells called the aleurone, which accounts for $6-7 \%$ of the grain and comprises about 34 to $40 \%$ fiber with high contents of minerals, vitamins and phytochemicals, covered by several protective layers of maternal origin (notably the pericarp and testa), which account for about $8 \%$ of the grain and comprise up to $50 \%$ fiber. These layers, together with the aleurone, form the bran fraction on milling, with the starchy endosperm forming white flour. Finally, the embryo (germ) accounts for less than 5\% of the grain and is rich in protein, minerals, vitamins and phytochemicals, and is usually recovered in the bran fraction on milling.

Wheat and other cereals are major sources of dietary fiber (DF) in the human diet (Steer et al. 2008). The major DF components in wheat grain are the cell-wall polysaccharides, arabinoxylan (AX) and (1-3)(1-4)- $\beta$-D-glucan ( $\beta$-glucan), which account for about $70 \%$ and $20 \%$, respectively, of the total cell wall polysaccharides in the starchy endosperm (and hence in white flour) (Mares and Stone 1973). DF can be fractionated on the basis of its solubility into soluble and insoluble forms, with consumption of insoluble DF resulting in lower transit time in the bowel and increasing fecal bulk, defecation frequency, and binding of carcinogens, whereas soluble fiber results in reduced serum cholesterol and glucose absorption in the small intestine and consequently lower postpandrial blood insulin levels (Moore et al. 1998; Lewis and Heaton 1999). Attenuation of blood cholesterol is related to reduced risk of developing coronary heart disease, whereas attenuation of blood glucose is related to reduced risk of type II diabetes. Apart from its health benefits DF also affects wheat functionality during cereal processing; for example, during breadmaking (Courtin and Delcour 2002) and gluten-starch separation (Frederix et al. 2004; Van Der Borght et al. 2005). Significant correlations have been observed between the contents of DF and environmental factors (Shewry et al. 2010). Gebruers et al. (2010) found that genotype determined about $50 \%$ or more of the variation observed in total (TOT)-AX and water-extractable (WE)-AX in wheat flour, WE-AX in bran and $\beta$-glucan in wheat wholemeal, whereas the impact of genotype $x$ environment $(\mathrm{GxE})$ interactions was relatively low. DF content of wheat is therefore highly heritable, and hence an appropriate target for plant breeding (Shewry et al. 2010). 
Although no breeding programs aimed at increasing AX have been reported in the scientific literature, several mapping populations have been developed to determine the genetic control of AX. The first population reported was a doubled haploid (DH) population derived from an intraspecific cross between Courtot and Chinese Spring, which was developed at the INRA plant breeding station at Clermont Ferrand (France). Cadalen et al. (1997) mapped 106 lines of this cross using restriction fragment length polymorphism (RFLP) probes. The second population (Leroy et al. 1997) consisted of 115 single-seed-descent (SSD) F $F_{7}$ lines derived from a cross between a synthetic amphiploid wheat W7984 (Synthetic) and a hard red spring wheat (Opata 85). These two mapping populations were used for genetic studies on the waterextractable arabinoxylan content of flour using relative viscosity (RV) of aqueous extracts of wholemeal as a measure, although the RV of the parental lines did not differ greatly $(1.8 \mathrm{v} 1.9$ in Courtot/Chinese Spring and 1.5 v 2 in Synthetic/Opata85) (Martinant et al. 1998). Later, Charmet et al. (2009) carried out a forward quantitative genetic approach using two recombinant populations derived from crosses between low WE-AX and high WE-AXparents. The French elite lines R6 and C7 (RE0006 and CF0007 DH lines) and the contrasting cultivars Valoris and Isengrain were used to develop two populations consisting of 125 and 280 doubled haploid (DH) lines, respectively, R6 and Valoris having low viscosity compared to C7 and Isengrain (with values of 1.2, 1.29 and 4.14, 3.19, respectively) (Quraishi et al. 2011).

Other conventional breeding efforts also targeted the improvement of dietary fiber content in wheat, but these were related to wheat components other than arabinoxylan. For example, high-amylose wheat genotypes were developed by combining mutations at the SGP-1 locus in order to increase the resistant starch content of flour (Rakszegi et al. 2015), and triple SGP-1 mutant wheat lines (SGP-A1B1D1 null) were tested in the $\mathrm{F}_{3}, \mathrm{~F}_{4}$, and $\mathrm{F}_{5}$ generations. The HvCslF6 gene from chromosome $7 \mathrm{H}$ of barley cv. Manasz was also transferred to wheat in order to increase the $\beta$-glucan level in the grain (Cseh et al. 2011). However, such improved lines have still not been released by commercially.

The simplest, most widely used method to increase the fiber content of white bread is to incorporate the bran fraction into flour (Bagdi et al. 2016; Bucsella et al. 2016). Previous studies, however, showed that the addition of fiber-rich fractions to wheat flour increased dough stiffness or stickiness. The bread baked from this type of flour had reduced loaf volume with denser, less aerated structure, and darker, harder crumb with no crispiness, so it was not popular with consumers (Ktenioudaki and Gallagher 2012; Sivam et al. 2010; Schmiele et al. 2012). These products were dark in color and the taste was bitter or astringent, due to the presence of other components, such as phenolic compounds, amino acids, small peptides, fatty acids and sugars (Heiniö et al. 2016; Rakha 2013).

The main aim of this work was therefore to develop improved types of wheat rich in dietary fiber, focusing on white flour, as this is preferred by the majority of consumers rather than wholemeal. A series of such lines was developed and the composition and physical and processing properties of the grain were determined.

\section{Materials and methods}

Plant materials 
The Chinese wheat cultivar Yumai-34 (released in 1988) was identified in the EU FP6 HEALTHGRAIN project as having high contents of both TOT-AX and WE-AX in white flour (Gebruers et al. 2008). In order to combine this high AX content with adaptation to European conditions and good breadmaking quality, crosses were made between Yumai 34 and three wheat varieties (Lupus, Mv-Mambo, and Ukrainka) with good adaptation traits under European environmental conditions: optimal plant growth development, good abiotic stress resistance (winter hardiness, sprouting resistance) and high productivity. Spikes from the $F_{2}$ segregating populations were planted in $F_{3}$ headrows. The plants were then selected for agronomic traits and high contents of water-extractable (WE) pentosans in flour (as a measure of AX) in each generation. After several cycles of selection 31 lines (12 Lupus/Yumai-34, three Mv-Mambo/Yumai-34, and 16 Ukrainka/Yumai-34) with higher than average contents of WE-pentosan and good agronomic properties were analysed in detail in the $\mathrm{F}_{7}, \mathrm{~F}_{8}$ and $\mathrm{F}_{9}$ generations (2013-2015), with the parental wheat varieties (Yumai-34, Lupus, Mv-Mambo, and Ukrainka) as controls.

\section{Growing conditions}

The lines were grown at the Agricultural Institute, Centre for Agricultural Research, Hungarian Academy of Sciences, Martonvásár (latitude, $47^{\circ} 21^{\prime} \mathrm{N}$; longitude, $18^{\circ} 49^{\prime} \mathrm{E}$; altitude, $150 \mathrm{~m}$ ) in 2012, 2013, and 2014. The plots were $2.5 \mathrm{~m}$ long with six rows spaced at $20 \mathrm{~cm}$. In the third year of the experiment the performance of the lines was compared in a field experiment with $6 \mathrm{~m}$ long plots organised in a randomised complete block design with three replicates. The soil was a chernozem with loam texture and $\mathrm{pH} 7.25$. The previous crops were oilseed rape (2011/2012) and oil radish (2012/2013 and 2013/2014). The plots were treated with herbicide (4 L/ha U-46 D-fluid SL containing 500 g/L 2-methyl-4chlorophenoxyacetic acid; $40 \mathrm{~g} /$ ha Granstar $50 \mathrm{SX}$ containing 50\% tribenuron methyl), insecticide ( $0.2 \mathrm{~L} /$ ha Karate Zeon $5 \mathrm{CS}$ containing $50 \mathrm{~g} / \mathrm{L} \lambda$-cihalotrin), and fungicide (first: 1 $\mathrm{L} / \mathrm{ha}$ Amistar Extra containing $200 \mathrm{~g} / \mathrm{L}$ azoxistrobin and $80 \mathrm{~g} / \mathrm{L}$ ciprokonazol, second: $1 \mathrm{~L} / \mathrm{ha}$ Cherokee containing $50 \mathrm{~g} / \mathrm{L}$ ciprokonazol, $62 \mathrm{~g} / \mathrm{L}$ propiconazol and $375 \mathrm{~g} / \mathrm{L}$ cloretalonil) each year. The growing conditions in the years of the experiment are summarised in Supplementary Table 1, showing that 2011/2012 had a very hot, dry summer with a very low minimum temperature in winter, while 2013/2014 had mild temperatures with high precipitation before harvest.

Physical grain properties

The test weight (TW, g seed/100 liter) (Foss Tecator 1241), thousand-kernel weight (TKW, g/1000 kernels) (MSZ 6367/4-86, Budapest: Hungarian Standards Institution), and hardness index (HI) (AACC method 55-31, Perten SKCS 4100) of the seeds were measured.

\section{Grain composition}

Five hundred g of seeds per sample were conditioned to $15.5 \%$ moisture content and milled with a Chopin CD1 Laboratory Mill to produce white flour. Crude protein content was determined by the Kjeldahl method, consistent with ICC method 105/2 (1995) using a FOSS Kjeltec 1035 Analyzer. Gluten content was measured with a Perten Glutomatic 2200 (ICC 137/1, 1995). In order to select lines with high AX, the contents of TOT- and WE-pentosans were determined using a colorimetric method as described by Douglas (1981). AX was also 
determined in each generation at Budapest University of Technology and Economics (BUTE) by GC of monosaccharides as described by Gebruers et al. (2009).

\section{Dough properties}

Dough properties (water absorption, dough development time, dough stability and dough softening) were measured with a Brabender Farinograph according to the ICC 115/1 standard (1995) method. Gluten index was calculated according to the ICC 155 standard (1995), while the Zeleny sedimentation, related to loaf volume, was measured with the ICC 116/1 method (1997) using the SediCom System (developed at BUTE and produced by LabIntern Ltd, Hungary, Tömösközi et al. 2009).

\section{Statistical analyses}

Least significant differences and correlations were calculated using the Microsoft Excel program. Principal Component Analysis was carried out using Statistica 6.0. Yield performances of the varieties were compared by two-factor ANOVA and pairwise comparisons with linear mixed model analysis in the Statistica 6.0 software.

\section{Results}

The physical, compositional, and processing properties of 31 agronomically attractive lines selected as combining high TOT- and WE-AX in flour were studied by field trials on the $\mathrm{F}_{7}$, $\mathrm{F}_{8}$, and $\mathrm{F}_{9}$ generation lines (2013-2015).

Physical properties

Test weights (TW) of the lines ranged from 70.45 to $82.97 \mathrm{~g} / 100 \mathrm{~L}$, whereas the lowest and highest values of the controls were 76.93 (Yumai-34) and $82.07 \mathrm{~g} / 100 \mathrm{~L}$ (Lupus). Lupus/Yumai-34 (LU/YU_4) and Ukrainka/Yumai-34 (UK/YU_15) lines had the highest test weights $(80.17,82.97 \mathrm{~g} / 100 \mathrm{~L}$, respectively), while the Ukrainka/Yumai-34 (UK/YU_1, 6, 7) lines had the lowest $(70.45,71.83$, and $71.67 \mathrm{~g} / 100 \mathrm{~L}$, respectively) values (Fig. 1a).

Thousand-kernel weights (TKW) of the lines ranged from 35.36 to $57.39 \mathrm{~g}$. This was much greater than the range of the controls, which was from 41.15 to $49.91 \mathrm{~g}$, with Ukrainka having the lowest and Yumai-34 the highest value. Two of the Mv-Mambo/Yumai-34 (MA/YU_2, 3) lines had higher TKWs than Yumai-34, whereas nine lines had similar TKWs to Yumai-34 (Fig. 1b). Flour yields varied from 50.03 to $61.50 \%$ compared with about $60 \%$ for the controls and were positively correlated with TKW ( $\mathrm{r}_{5 \%}=0.341$, Fig. $\left.1 \mathrm{c}\right)$. All of the parental lines and the breeding lines had hard kernel texture, with the hardness index showing a strong negative correlation with flour yield $\left(\mathrm{r}_{0.1 \%}=-0.69\right)$ (Table 1$)$.

\section{Grain composition}

Most of the breeding lines contained similar or significantly higher protein contents than the three European parents. The protein contents of the breeding lines ranged from 10.7 to $16.2 \%$, whereas the controls had about $12 \%$ protein and Yumai-34 had the highest protein content (14.5\%). Breeding lines derived from crosses with Lupus had the highest protein contents (LU/YU_12,10,9,8) (Fig. 2a). 
The gluten contents of the breeding lines showed similar variation to total protein content, varying from 23.90 to $38.47 \%$. The two components were highly correlated $\left(\mathrm{r}_{5 \%}=0.931\right)$. This wide variation probably resulted from differences in gluten contents of the parental varieties, with Ukrainka having the lowest $(24.97 \%)$ and Yumai-34 $(36.27 \%)$ the highest values. The best breeding lines (LU/YU_8,9,10,12) had the highest contents of gluten as well as total protein and would therefore be expected to have the best breadmaking quality (Fig. 2b).

The starch contents of the breeding lines ranged from 54.8 to $61.5 \%$ (Fig. 2c) and were negatively correlated with total protein and gluten contents ( -0.502 and -0.527 , respectively). This was in the same range as the control lines, which contained 56.6-59\% starch with Yumai-34 having the lowest value.

The main aim of the selection was to identify lines with high stable contents of AX, and particularly WE-AX, in white flour (determined as pentosans using a colorimetric method in the $\mathrm{F}_{3}$ to $\mathrm{F}_{9}$ generations). Consequently, most of the selected lines had increased levels of AX compared to the three control cultivars (Lupus, Mv-Mambo, Ukrainka). The TOT-AX contents of the selected lines ranged from 15.44 to $23.67 \mathrm{mg} / \mathrm{g}$, with ten lines (five Ukrainka/Yumai-34, and five Lupus/Yumai-34) having significantly higher TOT-AX contents than Yumai-34, and most of the other lines having higher TOT-AX contents than the parental controls (Fig. 2d). WE-AX content was lowest in Ukrainka $(5.43 \mathrm{mg} / \mathrm{g})$ with Yumai-34 containing almost twice as much $(9.47 \mathrm{mg} / \mathrm{g})$. The WE-AX content in the breeding lines ranged from $7.41 \mathrm{mg} / \mathrm{g}$ (similar to the contents in Lupus and Mv-Mambo) to $10.24 \mathrm{mg} / \mathrm{g}$ (higher than in Yumai 34), with twenty-seven lines having WE-AX contents greater than 8 $\mathrm{mg} / \mathrm{g}$ (Fig. 2e).

In years 2 and 3 ( $\mathrm{F}_{8}$ and $\mathrm{F}_{9}$ generations) $\mathrm{AX}$ was also determined as monosaccharides with GC, which gave values similar to or slightly lower than those determined as pentosans (Fig. $3 \mathrm{a}, \mathrm{b})$. This was expected, because the spectrophotometric method measures total pentosans, which include a small proportion of other pentose-containing polysaccharides such as arabinogalactan peptide (AGP). The monosaccharide analyses also allowed the arabinose:xylose (A:X) ratios of TOT-AX and WE-AX to be calculated; these were in the ranges $0.525-0.845$ and $0.550-0.760$, respectively, in the breeding lines (Yumai-34 having $\mathrm{A}: \mathrm{X}$ ratios of 0.685 and 0.670 in TOT-AX and WE-AX, respectively) (Fig. 3c).

\section{Processing properties}

The high protein and gluten contents of some of the breeding lines indicated that they could have good breadmaking properties. However, limited variation was observed in the gluten index (GI) of the lines (Fig. 4a), with most having GI values above 80 (except MA/YU1-3). Wider variation was found for Zeleny sedimentation $(24.33$ - $47.67 \mathrm{ml}$ ) (Fig. 4b) most lines having values of $35 \mathrm{ml}$ or greater, which were similar to, or significantly higher than, those of the control varieties.

The stability of the dough during mixing, measured with the Farinograph, ranged between 6.26 and 18.47 minutes, showing that they had good rheological properties. The MA/YU lines had the lowest dough stabilities, significantly below that of the Mv-Mambo control, while the UK/YU lines had the highest dough stabilities (from 10.46 to $18.30 \mathrm{~min}$ ) (Fig. 4c).

Farinograph dough softening was low and there were no significant differences between samples, except for those lines having the highest dough softening, namely, Mv-Mambo lines 3 (57.33 FU) and 2, Lupus lines 3 and 5 and Ukrainka lines 15 and 11. The lowest softening value was $8.33 \mathrm{FU}$ in Lupus line 2 (Fig. 4d). Farinograph dough development time in most of the lines was greater than ten minutes, with the curve increasing steadily until reaching the maximum value, indicating high dough stability. The Mv Mambo lines (MA/YU) had the 
shortest dough development time (4.23 $\mathrm{min})$, and the Lupus lines the longest (20 min) (Fig. 4e). Farinograph water absorption (WA) of the lines ranged from 56.7 to $65.7 \%$, with most of the lines having values greater than $60 \%$. This high WA could be related to the higher fiber content of the flour, as arabinoxylan has a higher water absorption capacity than the other major grain components (gluten proteins and starch) (Kweon et al. 2011). Hence the water absorption of Yumai-34 was $62.95 \%$ while that of Ukrainka, which has only half the AX content, was $58.23 \%$ (Fig. $4 f$ ).

\section{Principal component analysis (PCA)}

PCA was carried out to compare the lines based on multiple traits (Fig. 5). PCs 1 and 2 together accounted for $54.8 \%$ of the total cumulative variance. $\mathrm{PC} 1$ accounted for $31.51 \%$ of the total cumulative variance, with starch content having a positive effect and Zeleny sedimentation, TOT-AX content, and protein content negative effects; PC2 accounted for $23.29 \%$ of the total cumulative variance with TKW and GI having positive and negative effects, respectively. The analysis showed that higher protein content was associated with higher TOT-AX and WA, but lower starch content. Higher TKW was associated with lower GI and dough stability. Lines originating from crosses with Mv-Mambo had the highest TKW but the lowest quality, while Ukrainka lines had the best quality combined with high AX.

\section{Correlations between parameters}

Correlation analysis showed that TOT-AX was positively correlated with WA (0.48), gluten content (0.37) and WE-AX content (0.59) and negatively correlated with starch content ($0.54)$ flour yield (-0.46) and TW (-0.53) (Table 1). WE-AX was negatively correlated with flour yield (-0.40) and starch damage (-0.50). The protein and gluten contents of the flour were also correlated positively with WA ( 0.85 and 0.88 , respectively), as both components contribute to WA. The contents of protein and gluten also correlated negatively with dough stability (-0.38 and -0.48 , respectively), lines with extremely high protein and gluten contents having weaker dough properties. Interestingly, starch content correlated negatively with WA of the flour (-0.59). Starch damage (0.485), water absorption (0.621), and flour yield (-0.690) were all positively correlated with grain hardness, whereas ash content was positively correlated with water absorption (0.367) and negatively correlated with flour yield $(-0.522)$ and starch content $(-0.440)$.

\section{Yield analysis}

The 14 agronomically most promising lines (MA/YU_1, LU/YU_4-8, 10-11, UK/YU_3,4,6,7,8,15) were sown in three replications in a randomised complete block design in 2015 to determine yield performance compared to official Hungarian controls (Mv-Nádor, Mv-Lucilla, and Mulan) and to the parental lines. Two-factor ANOVA analysis and pairwise comparisons using linear mixed models showed that the yields of UK/YU_3,4 and MA/YU_1 were similar to those of the official controls, indicating that they are the most promising breeding lines. The UK/YU_8,15 and LU/YU_11 lines were also statistically similar to all the controls in pairwise comparisons (Supplementary Table 2), but had significantly lower yields than the official controls. Grain yield was not related to TOT-AX or WE-AX contents, but was negatively correlated with protein and gluten contents and with water absorption $(-0.626$, $-0.609,-0.560$, respectively) and positively correlated with the flour yield and starch content $(0.613,0.434)$ (Table 1). 


\section{DISCUSSION}

All of the selected lines had significantly higher WE-AX contents than the corresponding control genotypes (except for three lines). The increase in WE-AX content was greatest in the genetic background of Ukrainka, as this variety had the lowest WE-AX content among the parental wheat genotypes (Lupus, Mambo, Ukrainka). However, the Lupus lines had the highest absolute contents of WE-AX. Although the increased WE-AX content was expected to have the greatest effect on the technological properties of the dough, the situation was more complex.

Previous studies showed that the addition of fiber-rich fractions to wheat flour increased WA and dough development time, while dough stability and elasticity decreased and the dough was often stiff or sticky. Bread baked from this type of flour had reduced loaf volume with a denser, less aerated structure, darker, harder crumb and lack of crispiness (Ktenioudaki and Gallagher 2012, Sivam et al. 2010, Schmiele et al. 2012). These effects may have resulted from competition between the gluten and fiber for water, or by interactions between protein and fiber through ferulic acid (Bagdi et al. 2016; Bucsella et al. 2016; Noort et al. 2010).

WA was highest in Lupus/Yumai-34 lines 8,9,10 and 12, and probably resulted from the high contents of TOT-AX and protein in lines 8,9 and 10 and of protein only in line 12 . The lowest WA was in Ukrainka/Yumai-34 lines 6,7,14 and 15. Although the TOT-AX and WE-AX contents of these lines were significantly higher than that of the Ukrainka control they had the lowest protein contents. This low protein content may have accounted for their low WA, although the water-holding capacity of AX was five- to ten-fold higher than those of protein and starch (10, 2, $1 \mathrm{~g} / \mathrm{g}$, respectively) according to Wang et al. (2002). Consequently, AX affected the availability of the water to other dough components (Goesaert et al. 2005; Izydorczyk and Rattan 1995) and hence dough and bread quality.

Grain hardness determines starch damage during milling and has been used for decades in wheat breeding to select for higher WA. WA can also be increased by exploiting the water binding potential of soluble protein and pentosan components. Supplementing wheat flour with soluble proteins of different origins and polarities showed that polarity/hydrophobicity and charge distribution of albumins and globulins are the key features determining the amount of water required for hydration (Tömösközi et al. 2002). Pentosans form only small fraction of the flour (2-3\%) but are able to bind ten times their own weight of water and consequently may hold a quarter of the dough water (Kulp 1968). Similarly, it was shown that AX had a major effect on WA (Biliaderis et al. 1995; Courtin and Delcour 1998), with the high waterholding capacity of cross-linked AX polymers (obtained via oxidative coupling of feruloyl residues), affecting the distribution of moisture among dough constituents (Izydorczyk and Biliaderis 1992; Wang et al. 2003) and the rheological properties of the dough. Furthermore, AX reduces the availability of 'free' water in the dough that is available to hydrate starch and protein components, and to keep water soluble proteins fully in solution. The latter limits the ability of water-soluble proteins to form the thin liquid films required to stabilise the foamlike structure and the gas-holding capacity of the dough (Hoseney 1984; Salt et al. 2005).

The dough development times of most of the breeding lines did not differ significantly from those of the low AX wheat parents, although a decrease was observed in some lines (which may be of interest to the processing industry). The dough stability was also similar to, or 
below, those of the controls, whereas dough softening showed the opposite trend, with similar or increased values compared to the controls. The Lupus/Yumai-34 6 and Ukrainka/Yumai-34 9 and 14 lines had the most stable and strongest dough with the lowest dough softening. These lines also have high gluten index, confirming that they have high dough strength and therefore would be expected to have good breadmaking quality.

Zeleny sedimentation showed that four Lupus/Yumai-34 lines $(8,9,10,12)$ combining high protein and TOT-AX contents also had the highest Zeleny sedimentation and therefore the highest expected loaf volume. Most of the other lines had similar expected loaf volumes to the control parents, except two of the Mv-Mambo lines (Mambo/Yumai-34 1 and 3) that had significantly higher Zeleny values than the Mv-Mambo parent.

Differences have been reported in the effects of water-extractable and unextractable AX on dough quality. Adding moderate amounts of WE-AX to white flour increased the water absorption, dough development time and loaf volume (up to 1.3, 1.3 and 0.9\% added WE-AX, respectively). However, addition of a higher amount of WE-AX decreased loaf volume and quality (Biliaderis et al. 1995). In our lines, increases in WE-AX content of flour by up to $0.5 \%$ and of TOT-AX by up to $1.0 \%$ resulted in positive changes in dough quality.

The improved processing quality of the high AX lines may have been due to the increased WE-AX fraction, which would be expected to increase the viscosity of the water located between the gluten molecules and the gas cells in dough. The high viscosity conferred by WE-AX may add strength and elasticity to films around the gas cells, protecting them from coalescence resulting from mechanical and thermal disruption and thereby improving gas retention during mixing, proofing and baking and leading to higher loaf volume and improved crumb structure (Courtin and Delcour 2002, Goesaert et al. 2005). By contrast, insoluble AX enhances gas cell coalescence and decreases gas retention time, leading to poorer bread quality (Courtin and Delcour 2002, Goesaert et al. 2005).

The optimum amount of $\mathrm{AX}$ that is required to maintain breadmaking quality while improving the dietary fiber content of cereal products depends on several factors, the molecular weight of AX, arabinose:xylose ratio, particle size of the fiber, ferulic acid content, and protein content all being important determinants of processing quality (Morales-Ortega et al. 2013). The arabinose:xylose (A:X) ratio is determined by substitution of xylopyranosyl residues (Ordaz-Ortiz and Saulnier 2005), with a higher A:X value reflecting higher substitution and higher molecular weight. The arabinose:xylose ratio of WE-AX in most of the lines was similar to that of Yumai-34, whereas the A:X ratio of TOT-AX was significantly lower in several lines than in Yumai-34. This indicates that the degree of substitution and molecular weight of WU-AX is lower in these lines, having a greater effect on end-use quality.

Biliaderis et al. (1995) and Courtin and Delcour (1998) reported that high molecular weight (HMW) AX had greater effects on water absorption and dough development time than lower molecular weight WE-AX. Although a lower amount of HMW AX polymer reduces negative effects on processing properties and breadmaking quality, the ability of AX to form highly viscous solutions decreases (Buksa et al. 2016). By contrast, the lower molecular weight (2-20 $\mathrm{kDa})$ and lower substitution number (0.5-0.6) of WE-AX compared with soluble AX (100$120 \mathrm{kDa}$ or $300-600 \mathrm{kDa}, 0.3-1.1$ ) (Saulnier et al. 2007) results in less negative effects on quality. 
Although the fiber content of white bread can be increased by the addition of exogenous fiber, the simplest and most widely used way to increase fiber is by incorporating part or all of the bran fraction. However, wholemeal and bran-enriched breads often have low loaf volume with dense crumb structure, dark color and bitter or astringent taste. These products therefore pose challenges for the baker and have low consumer acceptability. However, these negative effects do not result from the fiber components themselves but from other components in the bran, notably phenolic compounds, amino acids, small peptides, fatty acids and sugars (Heiniö et al. 2016, Rakha 2013). The development of wheat with high fiber in white flour will therefore combine health benefits with good processing properties and high consumer acceptability.

The aim was thus to increase the AX content of white flour, avoiding the need to incorporate bran. The negative correlation between flour yield and TOT-AX in white flour indicates that this was achieved and that the increased AX content was not due to contamination with bran during milling, and this is supported by the low ash content of the flours (between 0.05 and $0.6 \%$ with a mean of $0.32 \%$ in 35 samples). The low ash contents might have resulted from the milling process, as the Chopin CD1 mill produces flour with small particle size $(<180 \mu \mathrm{m})$ and lower bran content, than typical laboratory mills, which produce flour with particle size higher than $250 \mu \mathrm{m}$. The ash contents of the fractions were generally lower than those of commercial flour $(\sim 0.5 \%)$. However, it should be noted that the flour yields from the Chopin CD1 mill (50-60\%) were also lower than those from commercial milling, which may approach $80 \%$.

No significant correlations were found between the grain yield and the TOT-AX and WE-AX contents. However, grain yield was negatively correlated with protein, and gluten contents, and WA, and positively correlated with the starch content. A positive relationship was also identified between grain yield and flour yield. This is in agreement with the generally accepted rule that higher yields are usually associated with lower grain quality.

The physical properties of the seed and grain yield are also important properties for variety registration. The TWs and TKWs of the lines were appropriate for registration, being similar or higher than the parental controls. This is not surprising, as Yumai-34 also has good kernel characteristics. Although the lines had a small decrease in flour yield, this should not reflect the commercial performance where flour recovery is more effective, as noted above.

The yields of several of the lines were also competitive with those of the official control varieties (Mv-Lucilla, Mulan and Mv-Nádor), with three lines having yields acceptable for registration. Mambo/Yumai-34 line 1 has large kernels and high flour yield but a softer than average kernel type. However, its processing quality is only moderate, with GI=70, $10 \mathrm{~min}$ dough stability and Zeleny sedimentation $40 \mathrm{ml}$. Ukrainka/Yumai-34 lines 3 and 4 have smaller but harder kernels with average flour yield. Although protein $(\sim 11.5 \%)$ and gluten $(\sim 26 \%)$ contents were rather low, these lines had high GI $(\sim 95)$ and Zeleny sedimentation $(\sim 35 \mathrm{ml})$ values and a minimum of $10 \mathrm{~min}$ dough stability. Taking into account the variation in environmental conditions, 2013-2014 having higher than average temperatures and a rainy period before harvest, and 2011-2012 being rather dry with extreme temperatures in winter and summer $\left(-22.6,37.6^{\circ} \mathrm{C}\right)$, the properties of these lines are promising and demonstrate that increased fiber content can be combined with high yields and good processing properties. 


\section{CONCLUSIONS}

It was shown that it is possible to increase the contents of water-extractable and/or unextractable fiber in white flour without compromising grain yield and quality, by using traditional breeding to exploit genetic variation in bread wheat genotypes. The increases achieved $(0.5 \%$ increase in WE-AX and $1.0 \%$ increase in TOT-AX on a flour dry weight basis) should be sufficient not only to provide health benefits, but also to have a positive effect on the processing quality of the flour.

Acknowledgments This research and breeding activity was started with funding from the EU FP6 Healthgrain project (2005-2010) and is now financed by OTKA projects K 112169 and K 112179 and by the TÉT_12_JP_2014_0004 project.

\section{REFERENCES}

American Association of Cereal Chemists AACC Method 55-31 (1999) Single-kernel characterization system for wheat kernel texture. American Association of Cereal Chemists Approved Methods, St Paul, MN, USA

Bagdi A, Tóth B, Lörincz R, Szendi S, Gere A, Kókai Z, Sipos L, Tömösközi S (2016) Effect of aleurone-rich flour on composition, baking, textural, and sensory properties of bread. LWT-Food Science and Technology 65:762-769

Biliaderis CG, Izydorczyk MS, Rattan O (1995) Effect of arabinoxylans on bread-making quality of wheat flours. Food Chem 53:165-171.

Bucsella B, Molnár D, Harasztos AH, Tömösközi S (2016) Comparison of the rheological and end-product properties of an industrial aleurone-rich wheat flour, whole grain wheat and rye flour. J Cereal Sci 69:40-48

Buksa K, Nowotna A, Ziobro R (2016) Application of cross-linked and hydrolyzed arabinoxylans in baking of model rye bread. Food Chem 192:991-996.

Cadalen T, Boeuf C, Bernard S, Bernard M (1997) An intervarietal molecular marker map in Triticum aestivum L. em. Thell. and comparison with a map from a wide cross. Theor Appl Genet 94:367-374

Charmet G, Quraishi, UM, Ravel C, Romeuf I, Balfourier F, Perretant MR, Joseph JL, Rakszegi M, Guillon F, Bedő Z, Saulnier L (2009) Genetics of dietary fibre in bread wheat. Euphytica 170:155-168

Courtin CM, Delcour J (1998) Physicochemical and bread-making properties of low molecular weight wheat-derived arabinoxylans. J Agric Food Chem 46:4066-4073

Courtin CM, Delcour JA (2002) Arabinoxylans and endoxylanases in wheat flour breadmaking. J Cereal Sci 35:225-243

Cseh A, Kruppa K, Molnár I, Rakszegi M, Doležel J, Molnár-Láng M (2011) Characterization of a new 4BS.7HL wheat/barley translocation line using GISH, FISH and SSR markers and its effect on the $\beta$-glucan content of wheat. Genome 54:795-804

Douglas SG (1981) A rapid method for the determination of pentosans in wheat flour. Food Chem 7:139-145

Frederix SA, Van Hoeymissen K, Courtin CM, Delcour JA (2004) Water-extractable and water-unextractable arabinoxylans affect gluten agglomeration behaviour during wheat flour gluten-starch separation. J Agric Food Chem 52:7950-7956

Gebruers K, Courtin CM, Delcour JA (2009) Quantification of arabinoxylans and their degree of branching using gas chromatography. In: Shewry PR, Ward JL (eds) 
HEALTHGRAIN methods: Analysis of bioactive components in small grain cereals. AACC International Inc, St Paul, MN, USA, pp 177-189.

Gebruers K, Dornez E, Bedo Z, Rakszegi M, Fras A, Boros D, Courtin CM, Delcour JA (2010) Environment and genotype effect on the content of dietary fiber and its components in wheat in the HEALTHGRAIN diversity screen. J Agric Food Chem 58:9353-9361

Gebruers K, Dornez E, Boros D, Fraś A, Dynkowska W, Bedo Z, Rakszegi M, Delcour JA, Courtin CM (2008). Variation in the content of dietary fiber and components thereof in wheats in the HEALTHGRAIN diversity screen. J Agric Food Chem 56:9740-9749

Goesaert H, Brijs K, Veraverbeke WS, Courtin CM, Gebruers K, Delcour JA (2005) Wheat flour constituents: how they impact bread quality, and how to impact their functionality. Trends Food Sci Technol 16:12-30

Heiniö RL, Noort MWJ, Katina K, Alam SA, Sozer N, de Kock HL et al. (2016) Sensory characteristics of wholegrain and bran-rich cereal foods - A review. Trends Food Sci Technol 47:25-38

Hoseney RC (1984) Functional properties of pentosans in baked goods. Food Technol 1:114119

International Association for Cereal Science and Technology ICC 105/2 (1995) Determination of Crude Protein in Cereals and Cereal Products for Food and for Feed. International Association for Cereal Science and Technology, Vienna

International Association for Cereal Science and Technology ICC 115/1 (1995) Method for using Brabender Farinograph. International Association for Cereal Science and Technology, Vienna

International Association for Cereal Science and Technology ICC 116/1 (1997) Determination of the Sedimentation Value (according to Zeleny) as an Approximate Measure of Baking Quality. International Association for Cereal Science and Technology, Vienna

International Association for Cereal Science and Technology ICC 137/1 (1995) Mechanical Determination of the Wet Gluten Content of Wheat Flour (Glutomatic). International Association for Cereal Science and Technology, Vienna

International Association for Cereal Science and Technology ICC 155 (1995) Determination of Wet Gluten Quantity and Quality (Gluten Index ac. to Perten) of Whole Wheat Meal and Wheat Flour (Triticum aestivum). International Association for Cereal Science and Technology, Vienna

Izydorczyk MS, Biliaderis CG (1992) Effect of molecular size on physical properties of wheat arabinoxylan. J Agr Food Chem 40:561-566.

Izydorczyk MS, Rattan O (1995) Effect of arabinoxylans on bread-making quality of wheat flours. Food Chem 53:165-171

Ktenioudaki A, Gallagher E (2012) Recent advances in the development of high-fibre baked products. Trends Food Sci Technol 28:4-14

Kulp K (1968) Pentosans of wheat endosperm. Cereal Sci Today 13:414-419

Kweon M, Slade L, Levine H (2011) Solvent retention capacity (SRC) testing of wheat flour: Principles and value in predicting flour functionality in different wheat-based food processes and in wheat breeding-a review. Cereal Chem 88:537-552.

Leroy P, Negre S, Tixier MH, Perretant MR, Sourdille P, Gay G et al. (1997) A genetic reference map for the bread wheat genome - Triticum aestivum L. em. Thell. In: McGuire PE, Qualset CO (eds) Progress in Genome Mapping of Wheat and Related Species. Joint Proc 5th and 6th Public Workshops in the Triticeae Mapping Initiative. 
Report No. 18, University of California Genetic Resources Conservation Program, Davis, Calif, pp 134-140

Lewis SJ, Heaton KW (1999) The metabolic consequences of slow colonic transit. Am J Gastroenterol 94:2010-2016

Mares DJ, Stone BA (1973) Studies on wheat endosperm. I. Chemical composition and ultrastructure of the cell walls. Austr J Biol Sci 26:793-812

Martinant JP, Cadalen T, Billot A, Chartier S, Leroy P, Bernard M, Saulnier L, Branlard G (1998) Genetic analysis of water-extractable arabinoxylans in bread wheat endosperm. Theor Appl Genet 97:1069-1075

Moore MA, Beom Park C, Tsuda H (1998) Soluble and insoluble fiber influences on cancer development. Crit Rev Onco Hematol 27:229-242

Morales-Ortega A, Carvajal-Millan E, Lopez-Franco Y, Rascon-Chu A, Lizardi- Mendoza J, Torres-Chavez P, Campa-Mada A (2013) Characterization of water extractable arabinoxylans from a spring wheat flour: rheological properties and microstructure. Molecules 18:8417-8428

MSZ 6367/4-86 (1986) Edible, fodder and industrial seeds and husked products. Determination of test weight, thousand-kernel weight and classification grade. Budapest, Hungary: Hungarian Standards Institution. Available at: www.mszt.hu

Noort MWJ, van Haaster D, Hemery Y, Schols HA, Hamer RJ (2010) The effect of particle size of wheat bran fractions on bread quality - Evidence for fibre-protein interactions. $\mathrm{J}$ Cereal Sci 52:59-64

Ordaz-Ortiz JJ, Saulnier L (2005) Structural variability of arabinoxylans from wheat flour. Comparison of water-extractable and xylanase-extractable arabinoxylans. J Cereal Sci 42:119-125

Quraishi UM, Murat F, Abrouk M, Pont K, Confolent C, Oury FX et al. (2011) Combined meta-genomics analyses unravel candidate genes for the grain dietary fiber content in bread wheat (Triticum aestivum L.). Funct Integr Genomics 11:71-83

Pomeranz Y (1988) Wheat. Chemistry and Technology. AACC, St Paul, MN, USA

Rakha A (2013) Fibre-enriched and wholegrain bread. In: Delcour JA, Poutanen K (eds), Fibre-rich and wholegrain foods - Improving quality (First edit.). Woodhead Publishing Limited, Cambridge, UK, pp 211-230

Rakszegi M, Kisgyörgy NB, Kiss T, Sestili F, Láng L, Lafiandra F, Bedő Z (2015) Development and characterization of high-amylose wheat lines. Starch/Stärke 67:247254

Salt LJ, Robertson JA, Jenkins JA, Mulholland F, Mills ENC (2005) The identification of foam-forming soluble proteins from wheat (Triticum aestivum) dough. Proteomics 5:1612-1623

Saulnier L, Sado PE, Branlard G, Charmet G, Guillon F (2007) Wheat arabinoxylans: Exploiting variation in amount and composition to develop enhanced varieties. J Cereal Sci 46:261-281

Schmiele M, Jaekel LZ, Patricio SMC, Steel CJ, Chang YK (2012) Rheological properties of wheat flour and quality characteristics of pan bread as modified by partial additions of wheat bran or whole grain wheat flour. Int J Food Sci Technol 47:2141-2150

Shewry PR, Piironen V, Lampi A-M, Edelmann M, Kariluoto S, Nurmi T et al (2010) The HEALTHGRAIN wheat diversity screen: Effects of genotype and environment on the phytochemicals and dietary fiber components. J Agric Food Chem 58:9291-9298

Sivam AS, Sun-Waterhouse D, Quek S, Perera CO (2010) Properties of bread dough with added fiber polysaccharides and phenolic antioxidants: a review. J Food Sci 75:163-74 
Steer T, Thane C, Stephen A, Jebb S (2008) Bread in the diet: consumption and contribution to nutrient intakes of British adults. Proceedings of the Nutrition Society 67: E363. Cambridge University Press, UK

Tömösközi S, Békés F, Haraszi R, Gras PW, Varga J, Salgó A (2002) Application of Micro Z-arm mixer in wheat research - Effects of protein addition on mixing properties of wheat dough. Periodica Polytechnica 46:11-28.

Tömösközi S, Nádosi M, Balázs G, Cavanagh C, Morgunov A, Salgó A, Békés F (2009) Revival of sedimentation value - method development, quality prediction and molecular background. In: Branlard G (ed) Gluten Proteins. Proc $10^{\text {th }}$ Int Gluten Workshop, INRA, Clermont-Ferrand, France, pp.104-108

Van der Borght A, Goesaert H, Veraverbeke WS Delcour JA (2005) Fractionation of wheat and wheat flour in to starch and gluten: a review of main processes and the factors involved. J Cereal Sci 41:221-237

Wang J, Rosell CM, Benedito C, Barber D (2002) Effect of the addition of different fibres on wheat dough performance and bread quality. Food Chem 79:221-226

Wang MW, Oudgenoeg G, van Vliet T, Hamer RJ (2003) Interaction of water unextractable solids with gluten protein: effect on dough properties and gluten quality. J Cereal Sci 38:95-104 


\section{Figure Captions}

Fig. 1 Mean values of physical properties, a. Test weight (TW) (g/100 liter L), b. Thousandkernel weight $(\mathrm{TKW})(\mathrm{g})$, c. Flour yield (\%), of 31 selected lines and controls (black) examined in 2013-2015

Fig. 2 Mean compositional properties, a. Protein content (\%), b. Gluten content (\%), c. Starch content $(\%)$, d. Total-arabinoxylan content (TOT-AX) $(\mathrm{mg} / \mathrm{g})$, e. Water-extractable arabinoxylan content (WE-AX) (mg/g), of 31 selected lines and controls examined in 20132015

Fig. 3 Comparison of a. Total-arabinoxylan content (TOTAX) (mg/g) and b. Waterextractable arabinoxylan content (WEAX) measured spectrophotometrically (SP) and by gaschromatography (GC), and c. ratio of arabinose and xylose in TOTAX and WEAX measured by GC (means from 2014 and 2015)

Fig. 4 Mean breadmaking properties, a. Gluten Index (GI), b. Zeleny sedimentation (ml), c. Dough stability (min), and d. Water absorption (\%), of 31 selected lines and controls examined in 2013-2015

Fig. 5 Principal component analyses based on the physical, compositional, and breadmaking properties of the breeding lines (2013-2015 average) (AX - arabinoxylan, DevTime - dough development time, FY - flour yield, GI - gluten index, HunQN - Hungarian Farinograph quality number, Prot - Kjeldahl protein content, Stability - Farinograph dough stability, TKW - thousand-kernel weight, TOT - total, TW - test weight, Wabs - Farinograph flour water absorption, WE - water-extractable, Zeleny - Zeleny sedimentation. 

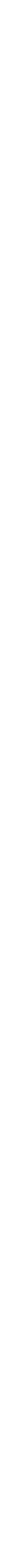
a. ${ }^{18} \quad \operatorname{LSD}_{5 \%}=0.4693$

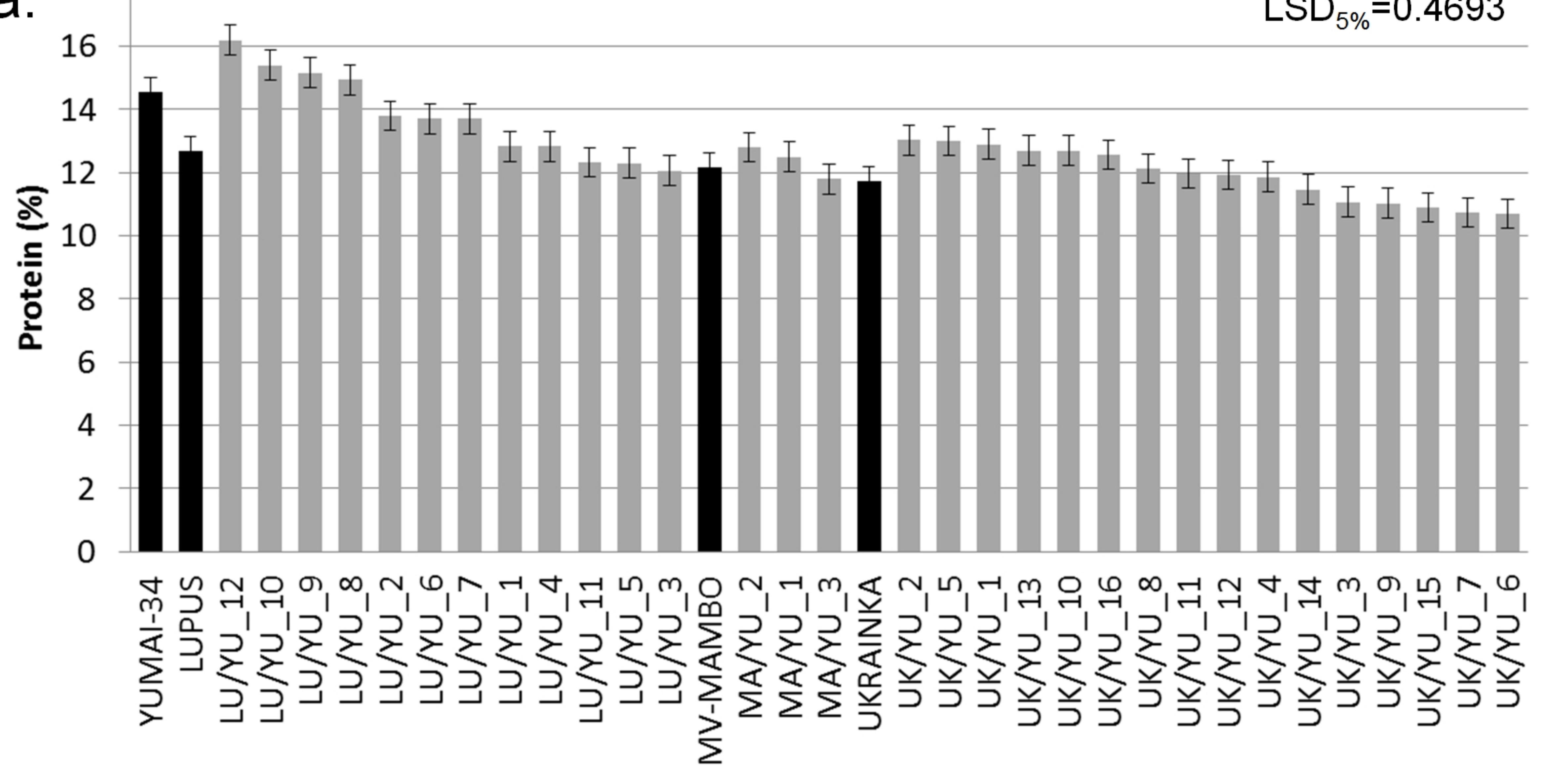

C. 70

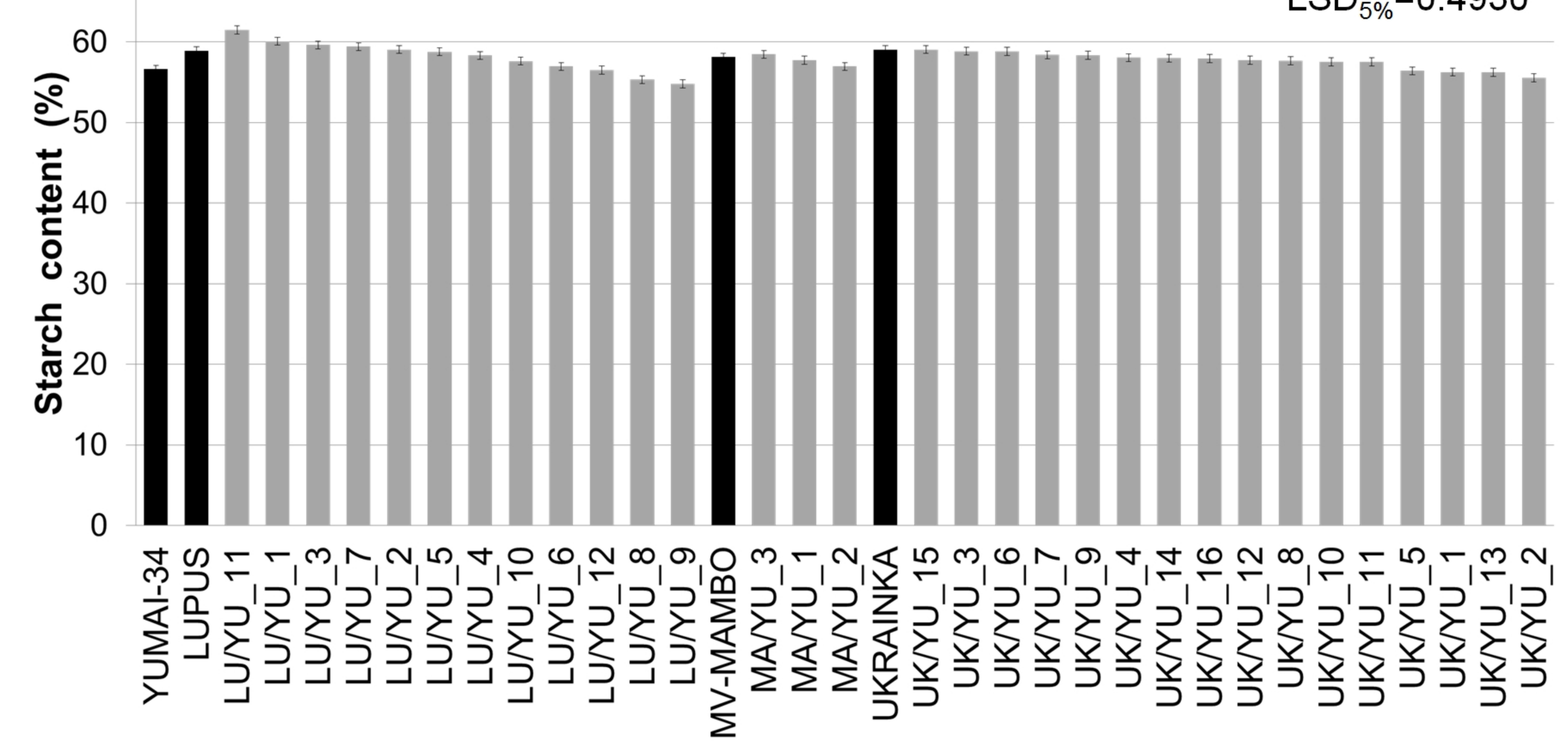

e.

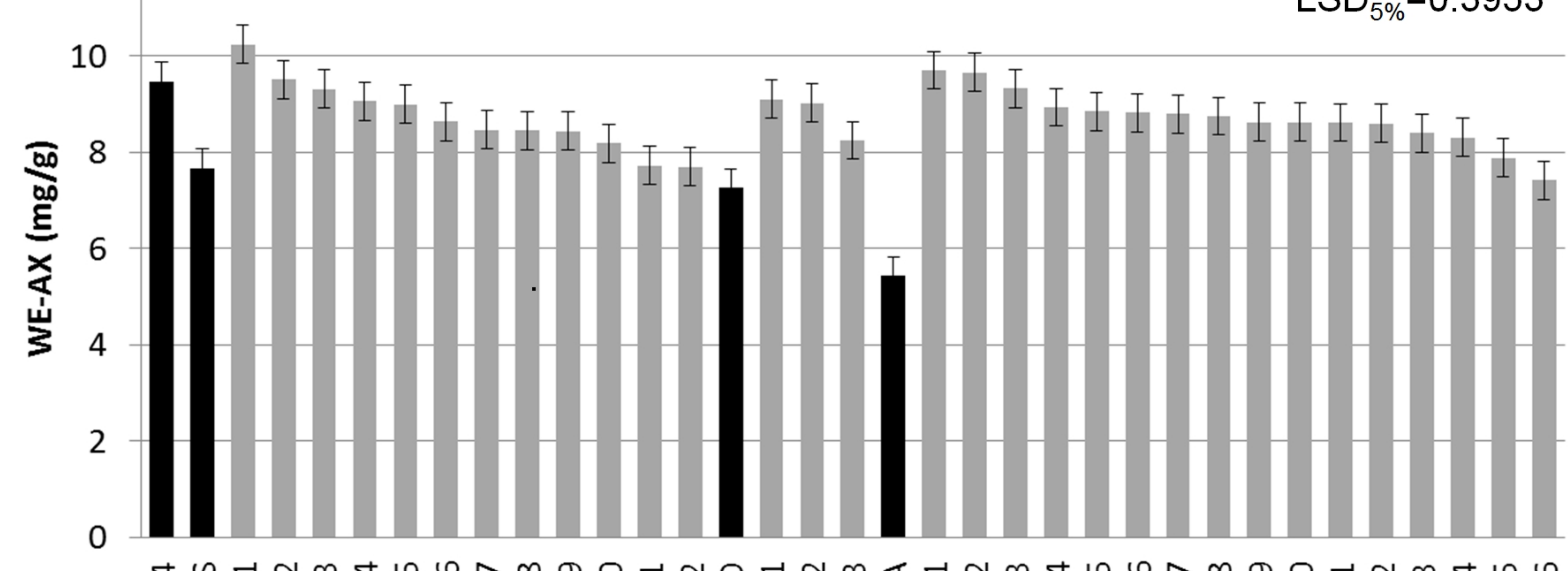

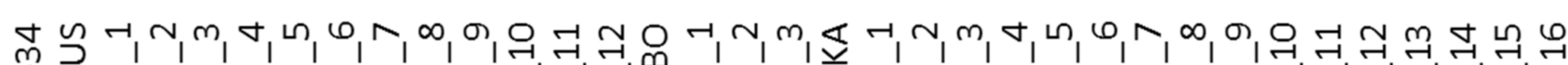

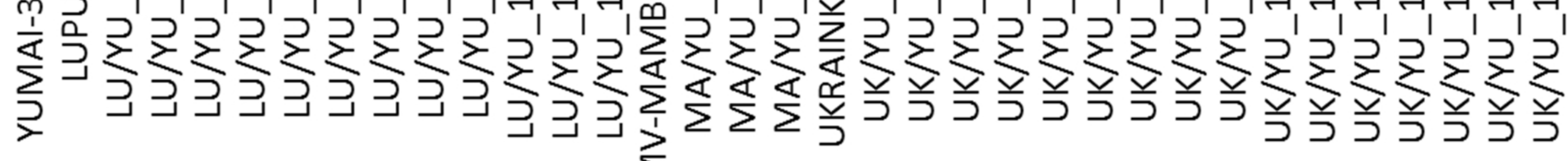

b. ${ }^{45}$

$\operatorname{LSD}_{5 \%}=1.5066$

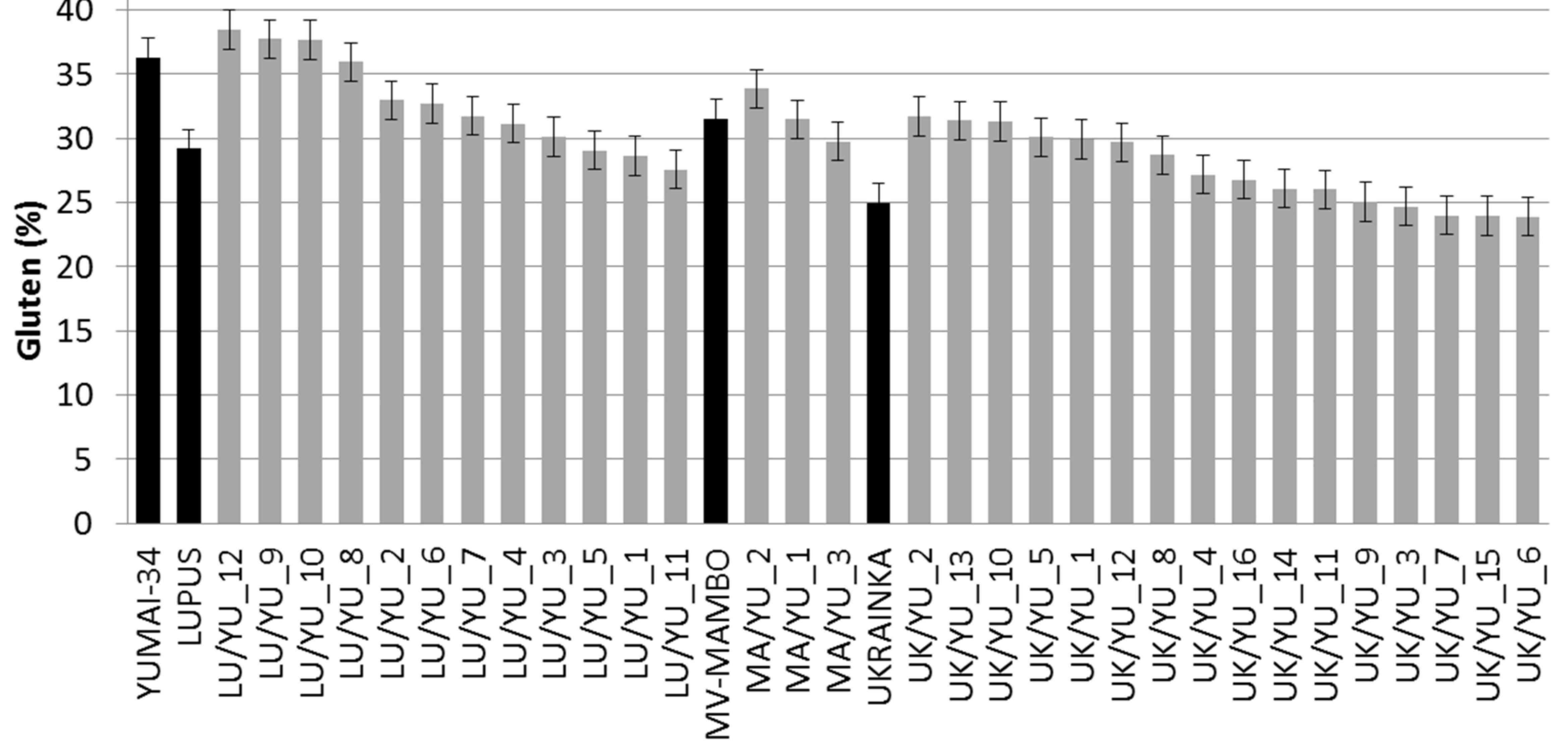

d. 30

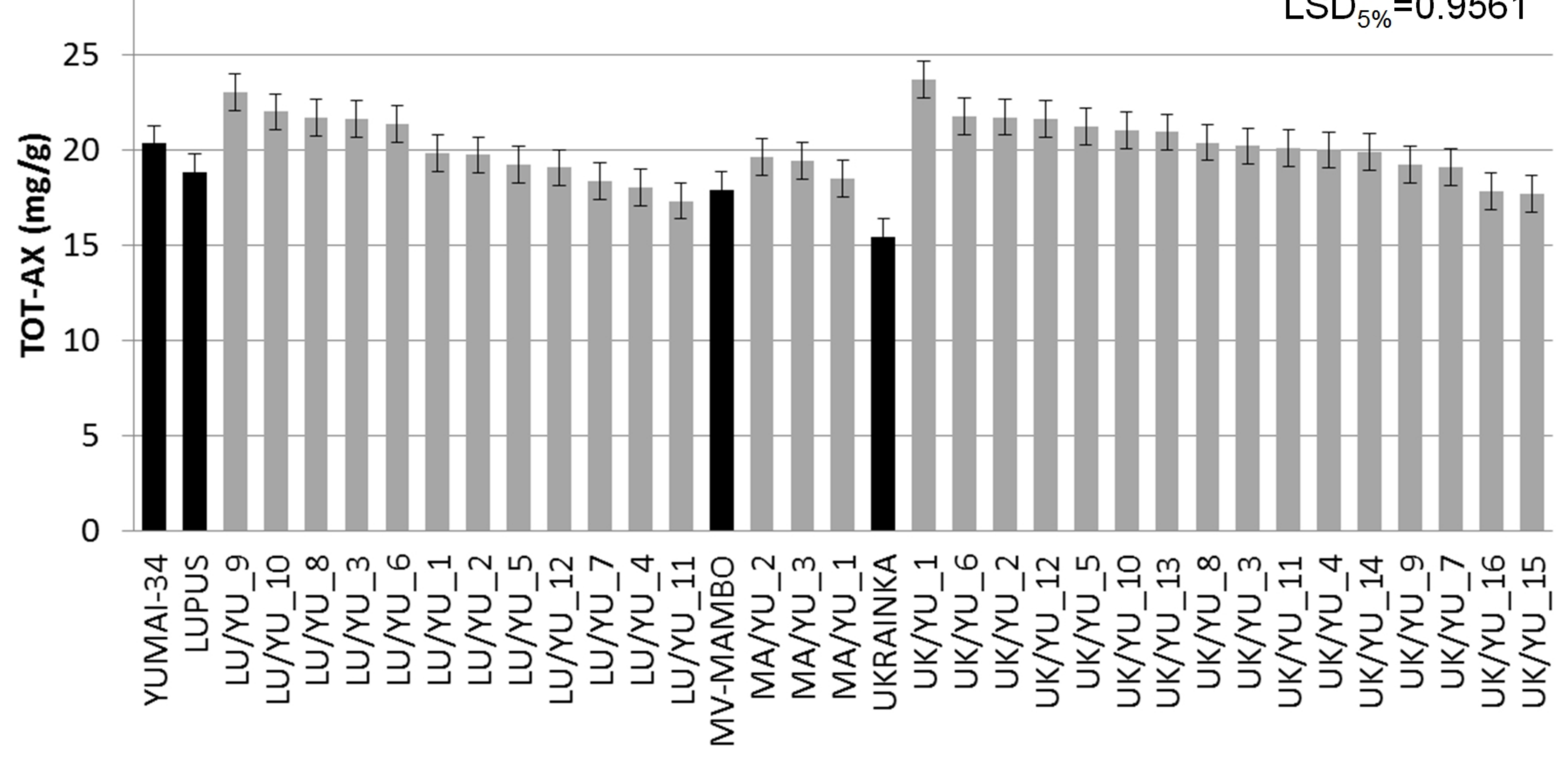


a. ${ }^{120} \quad \operatorname{LSD}_{5 \%}=3.1178$

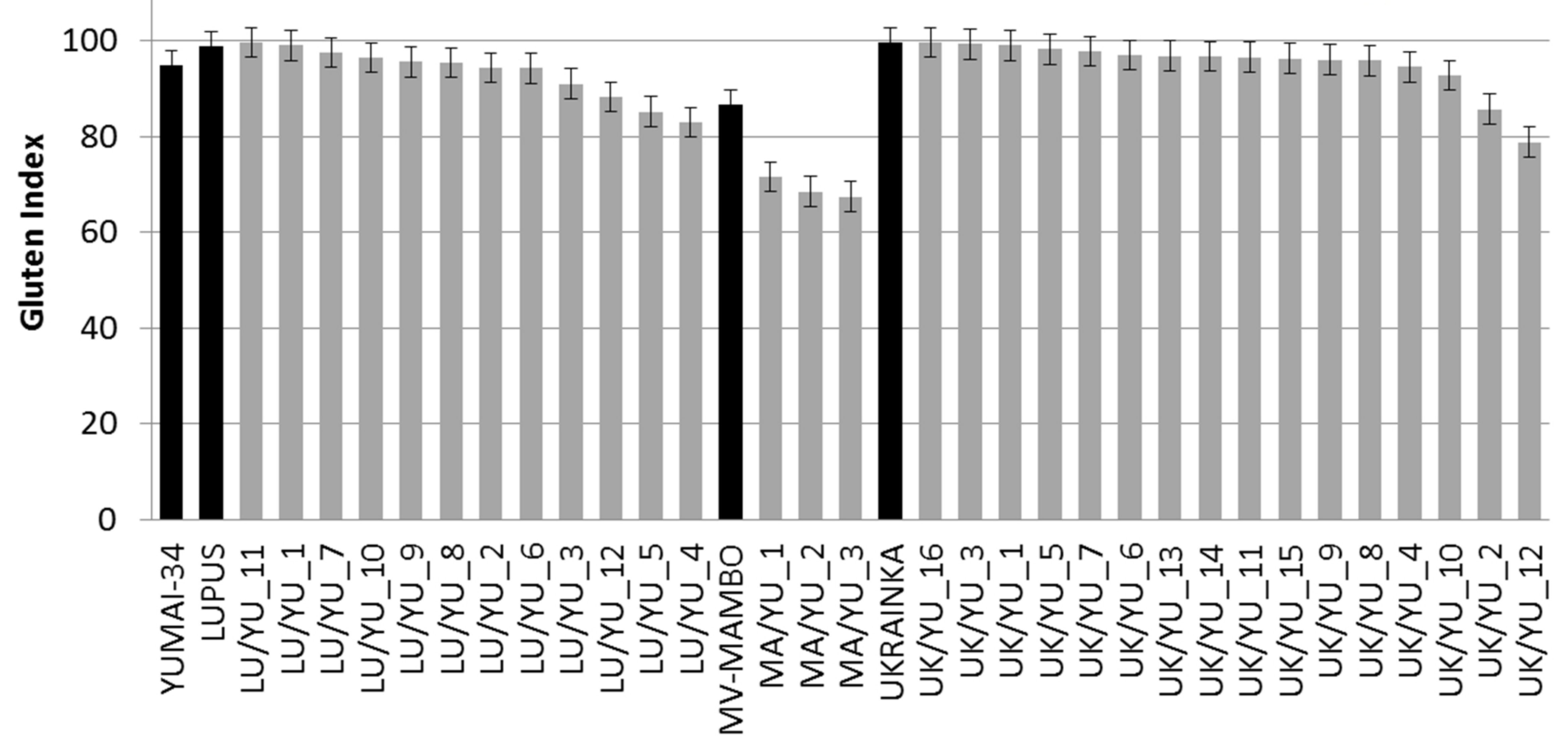

c.

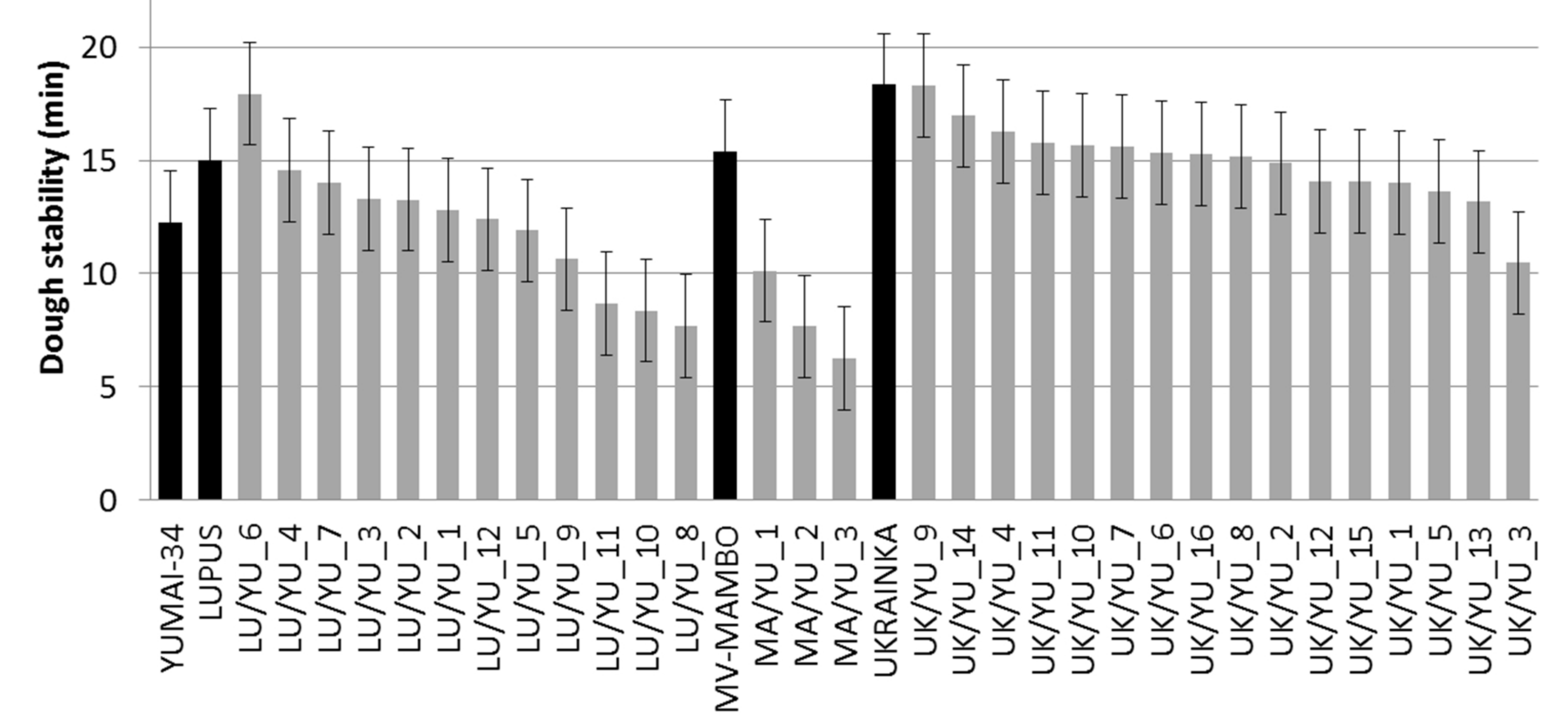

e.

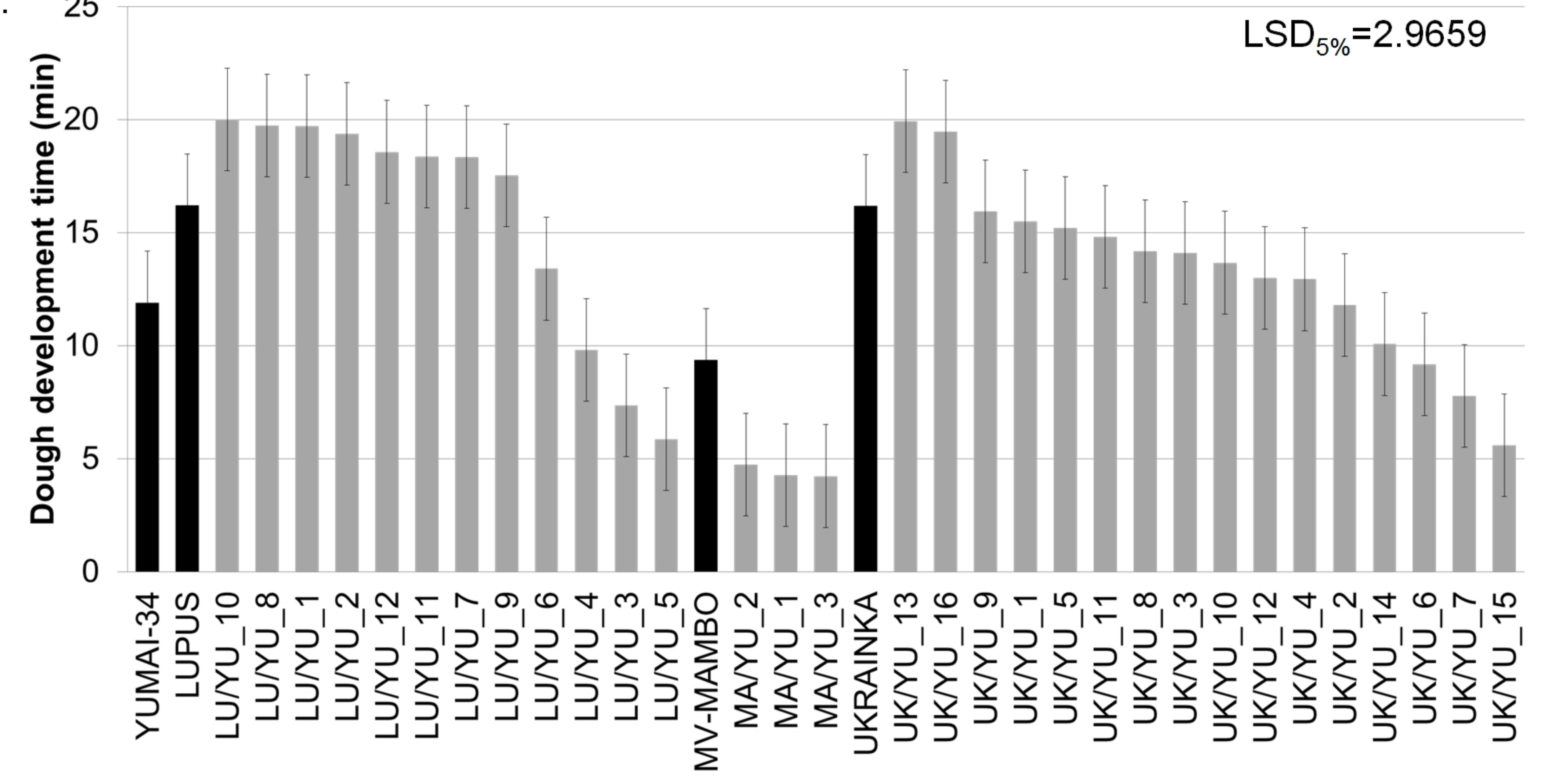

b. ${ }^{60}$

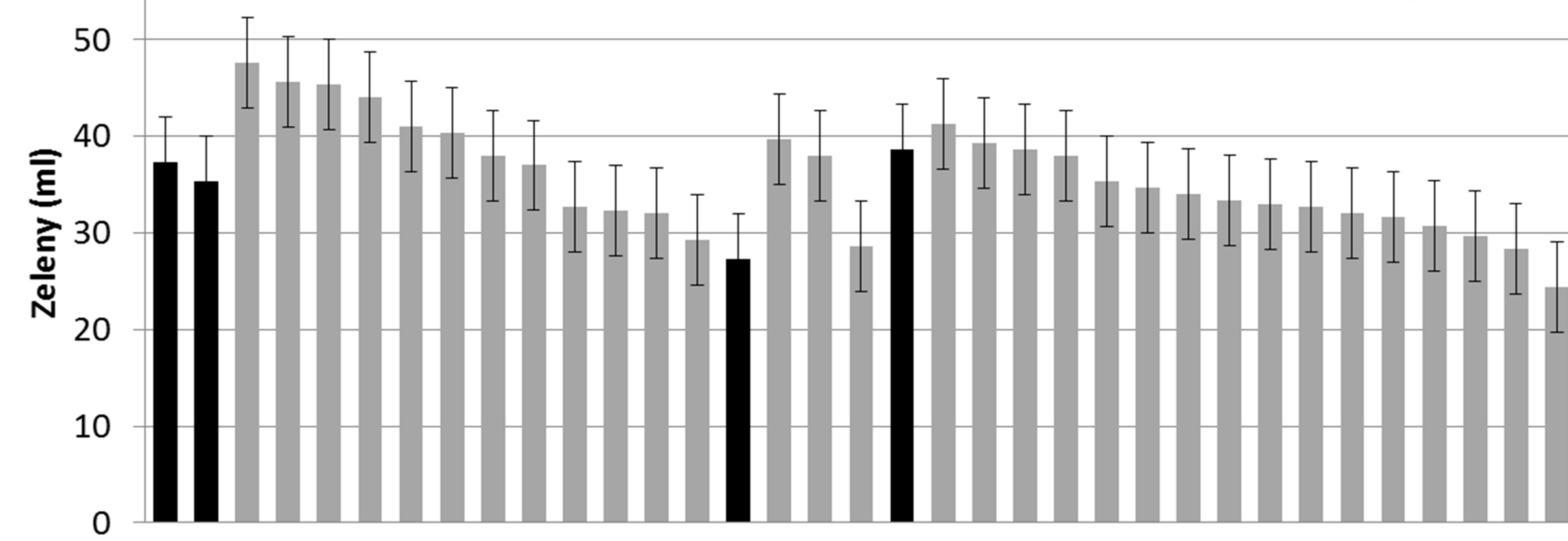

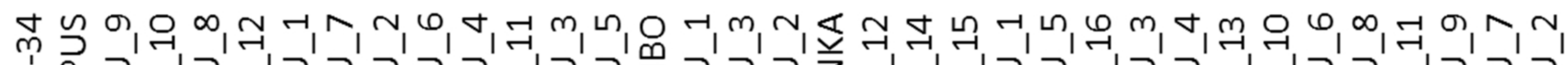

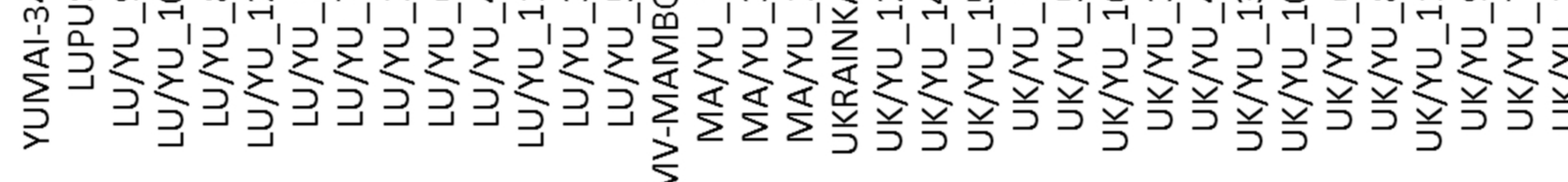

d. ${ }_{\text {胥 }}{ }^{70}$

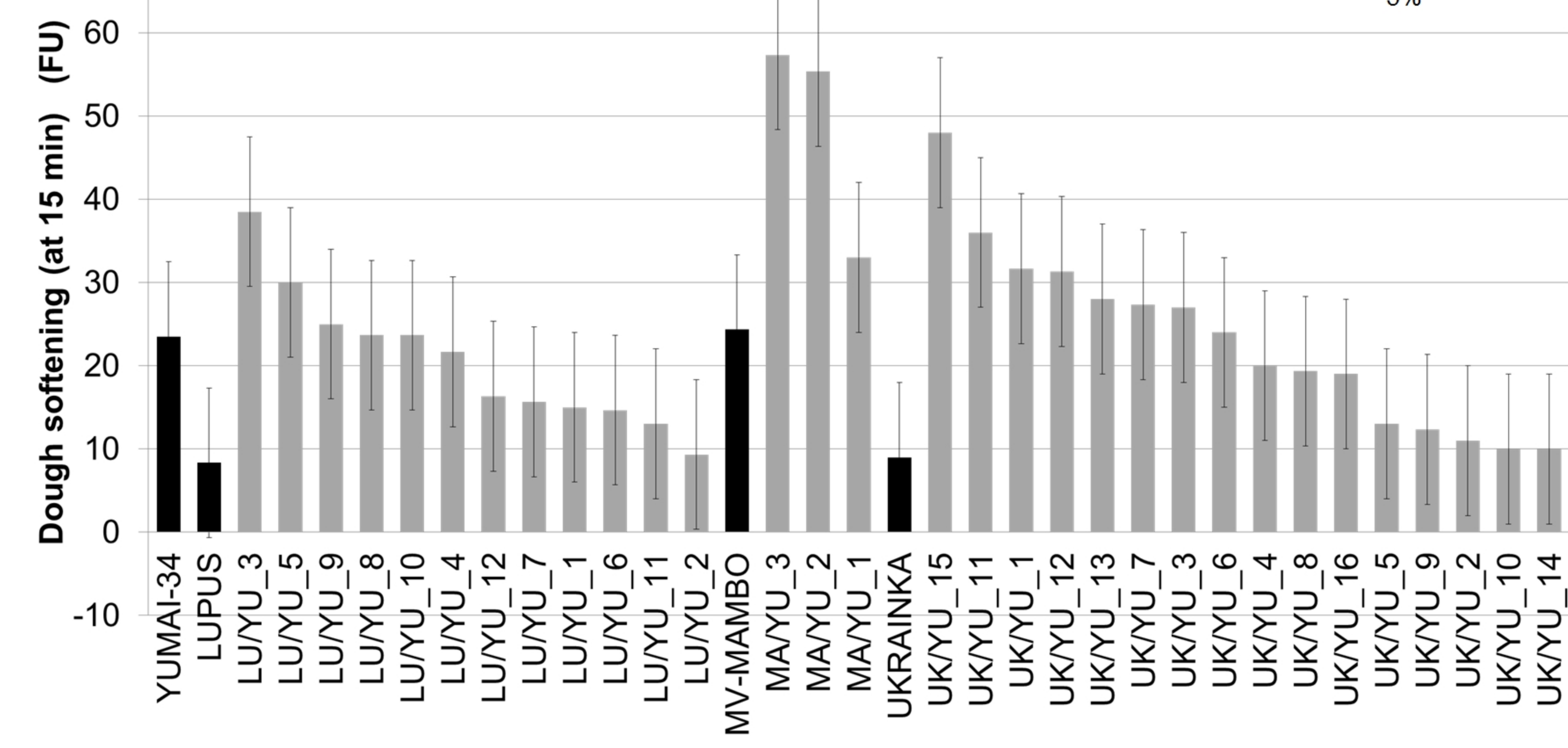

f. 68

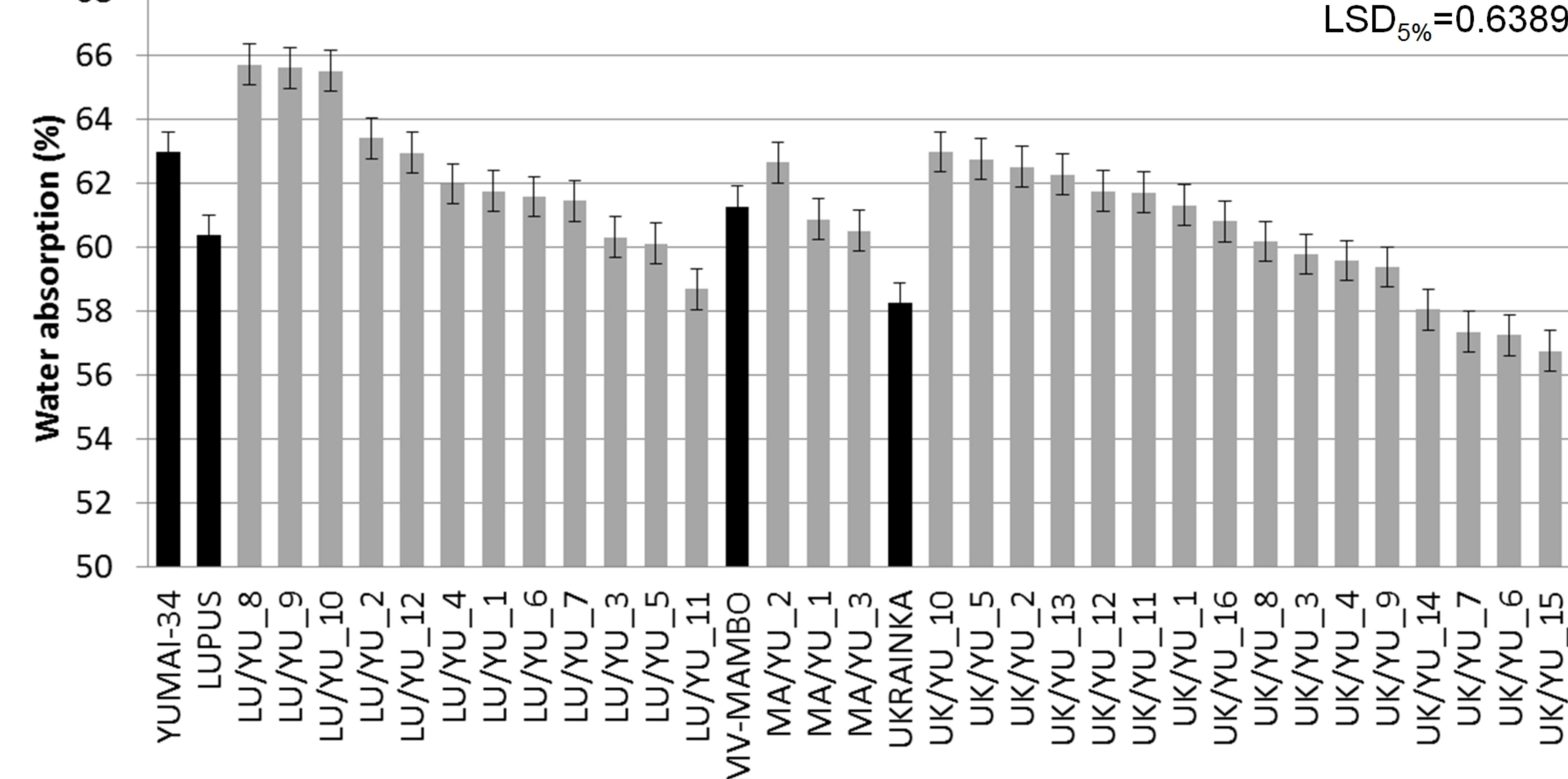



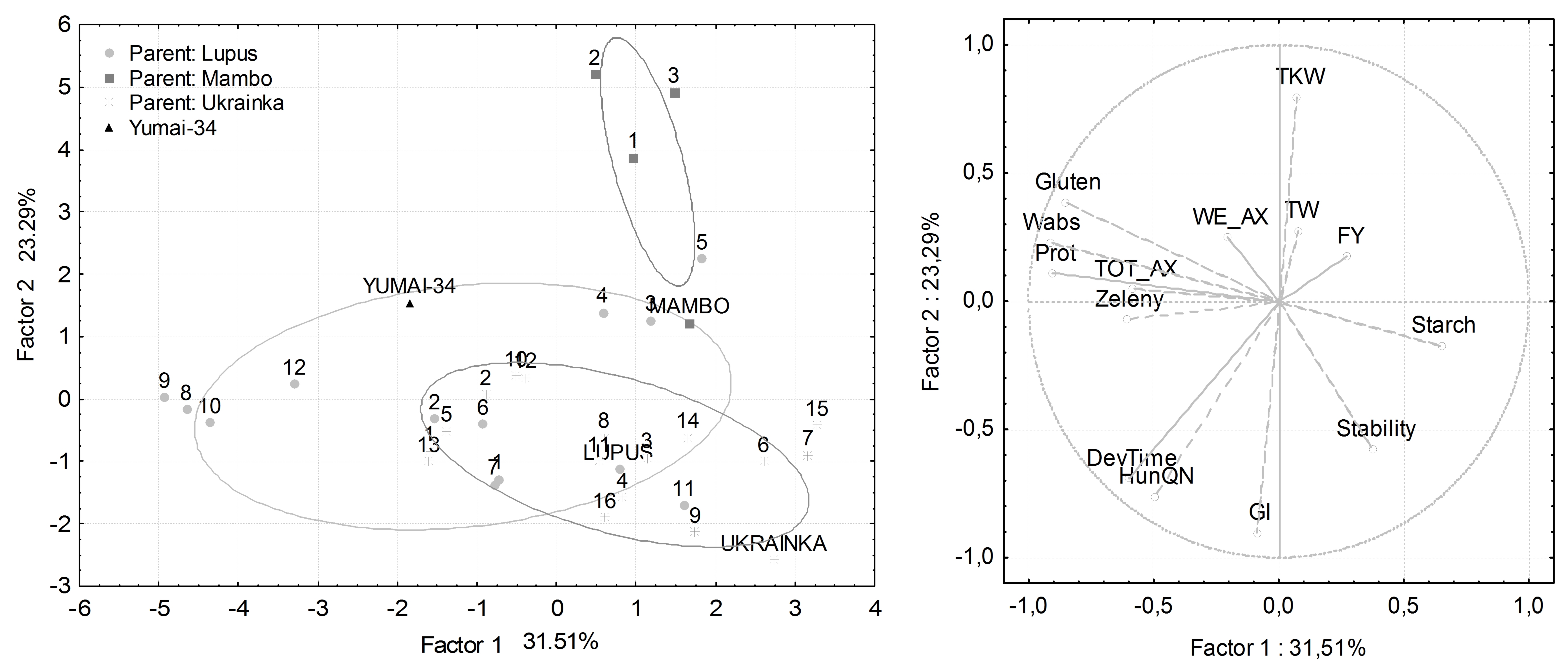
a. $25 \quad-$ TOT_GC $=$ TOT_SP

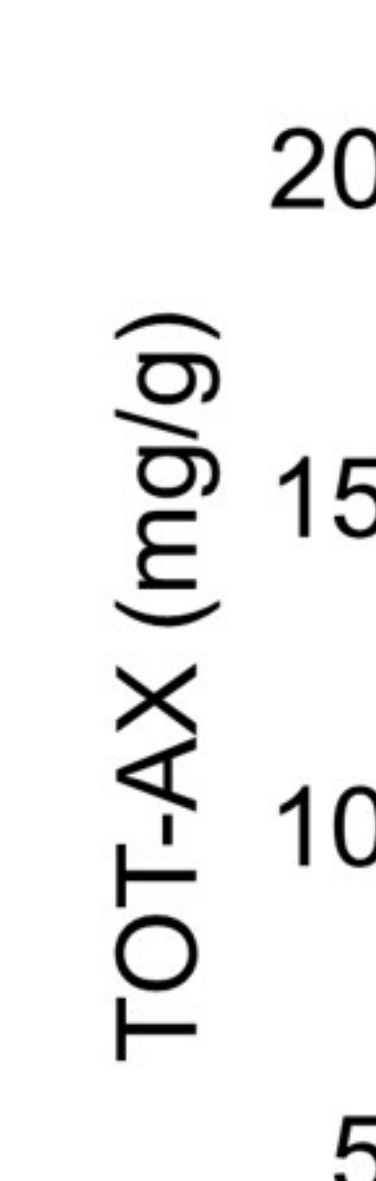

5

$$
0
$$

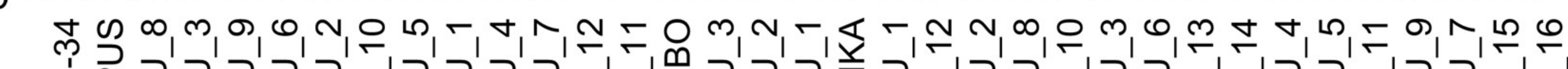

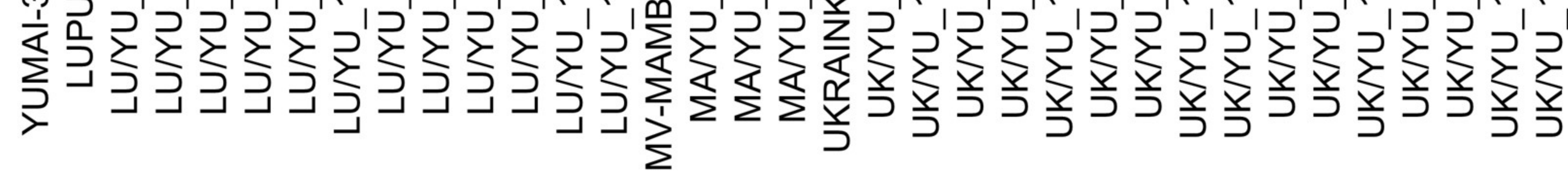

C.

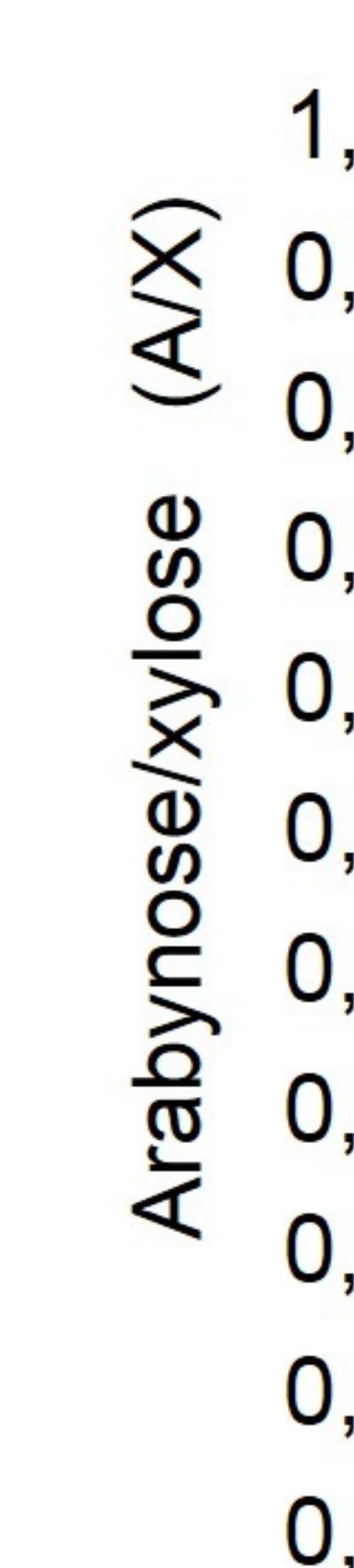

- TOTAX A/X $\square$ WEAX A/X

$\operatorname{LSD}_{5 \%}=0.085 \quad \operatorname{LSD}_{5 \%}=0.039$

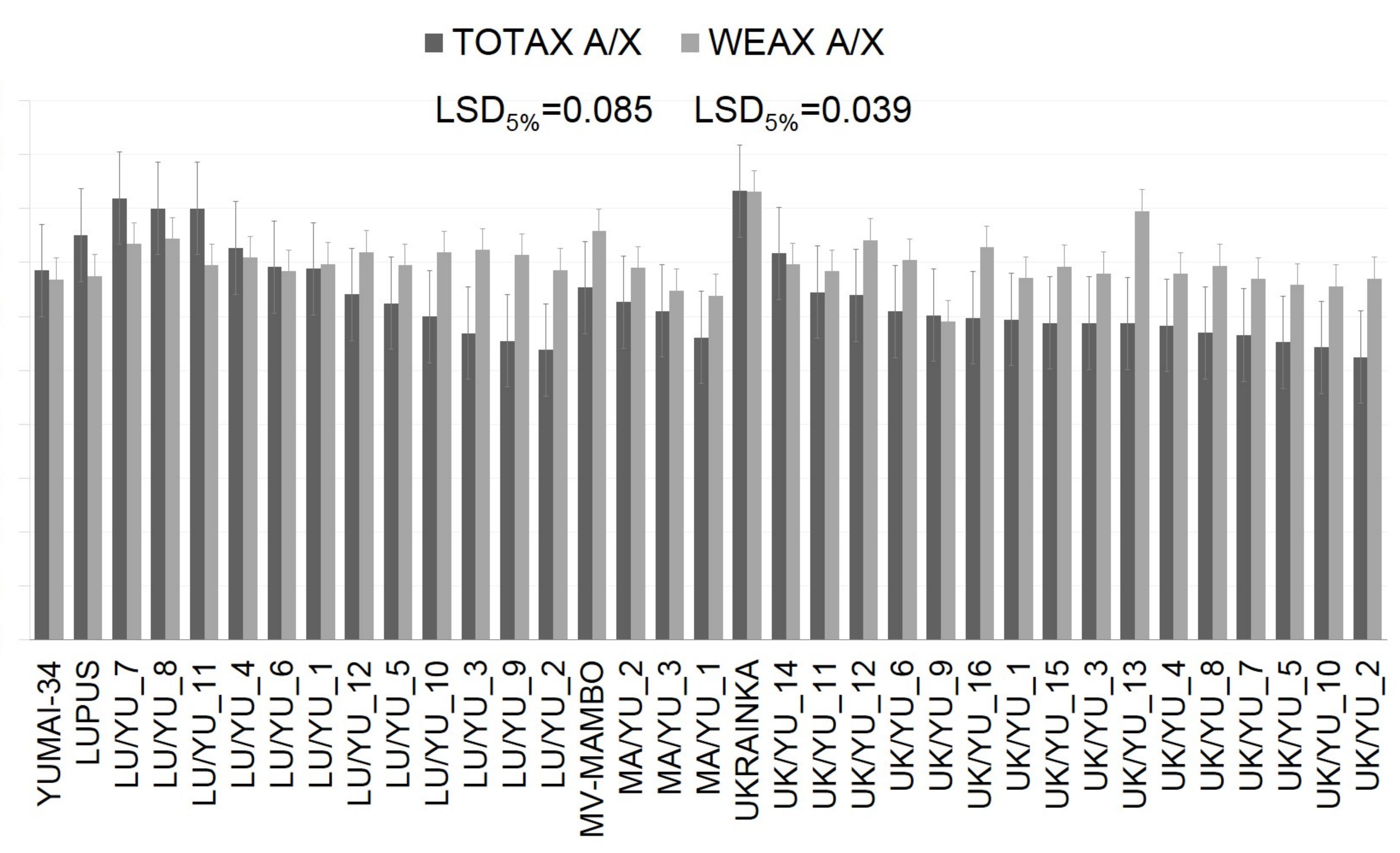

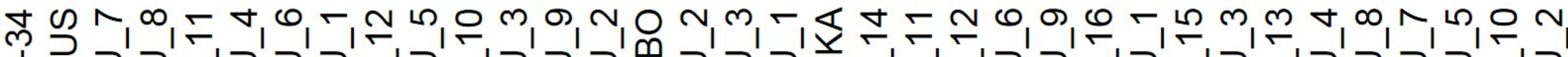

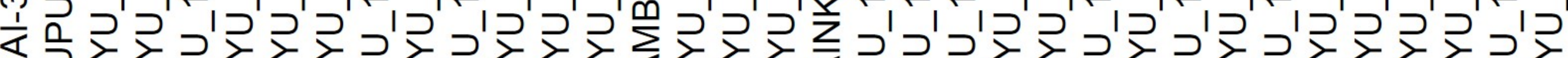

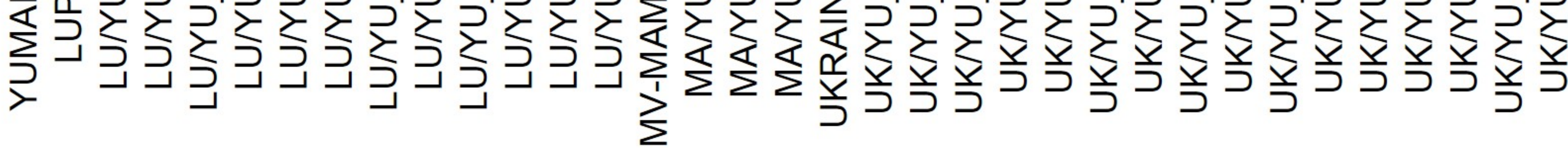

b.12 $\quad$ WE_GC $\square$ WE_SP

$\operatorname{LSD}_{5 \%}=0.32 \quad * \mathrm{LSD}_{5 \%}=2.84$

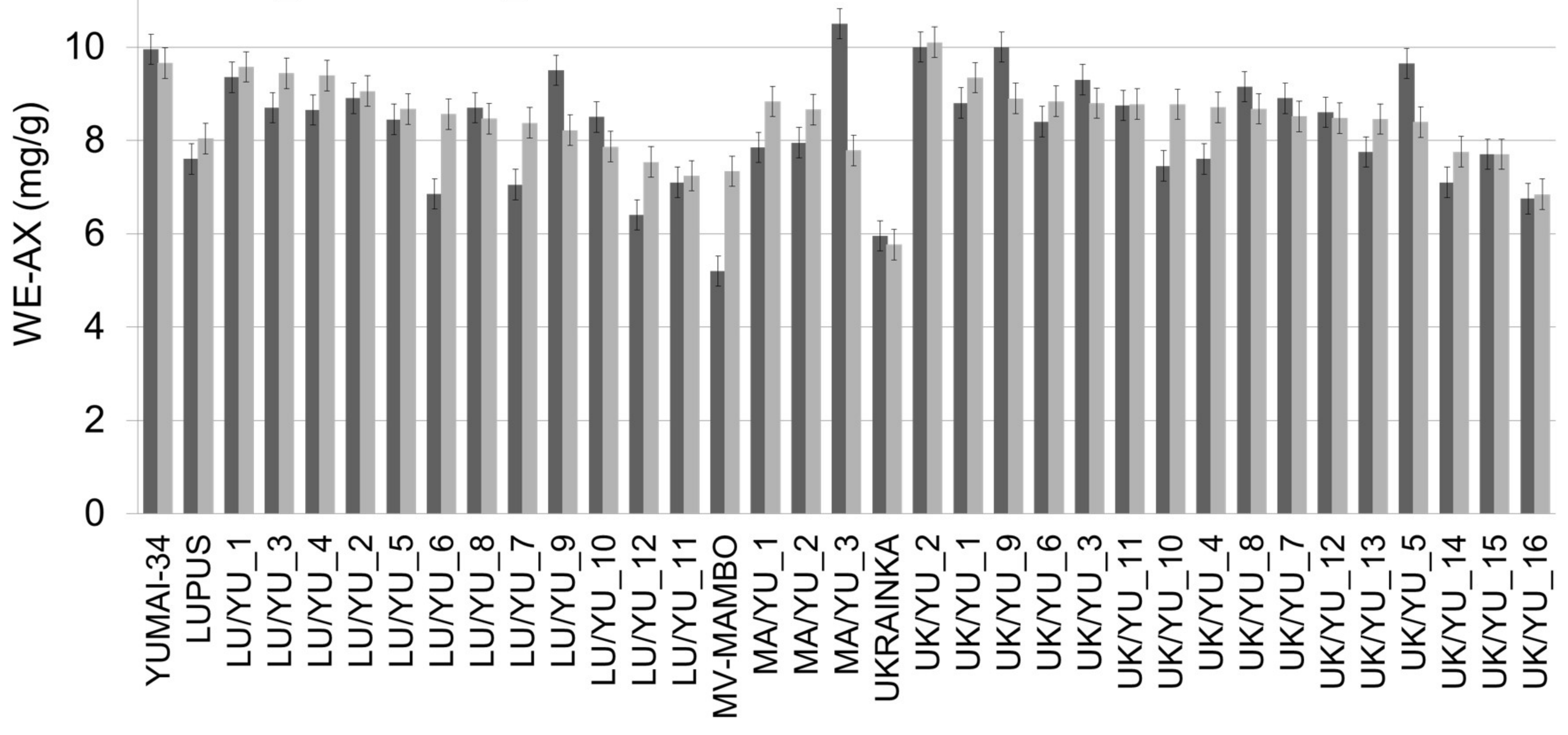

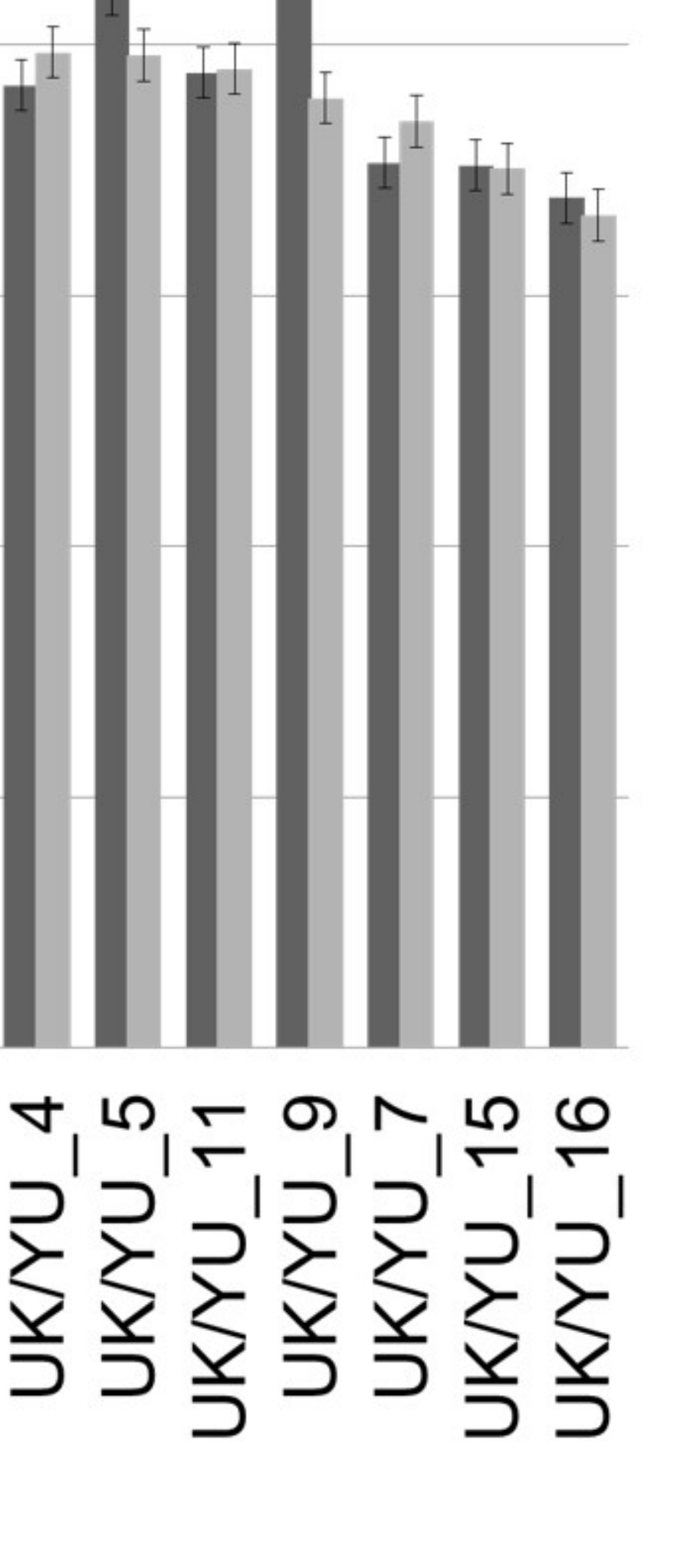

.


Supplementary Table 1. Main growing conditions in different years of the experiment (Martonvásár, 2012-2014)

\begin{tabular}{|c|c|c|c|c|}
\hline & Growing conditions & 2011/2012 & $2012 / 2013$ & $2013 / 2014$ \\
\hline \multirow{2}{*}{. ํㅗㅀ } & Geographic coordinates & \multicolumn{3}{|c|}{$47.3 \mathrm{~N}, 18.8 \mathrm{E}$} \\
\hline & Altitude & \multicolumn{3}{|c|}{$115 \mathrm{~m}$} \\
\hline \multirow{6}{*}{ 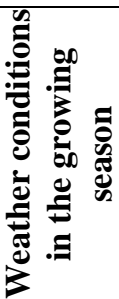 } & Total precipitation (mm) & 217.2 & 387.5 & 330.5 \\
\hline & Precipitation in the last 100 days (mm) & 129.6 & 122.5 & 185.4 \\
\hline & Maximum temperature $\left({ }^{\circ} \mathrm{C}\right)$ & 37.6 & 35.1 & 33.8 \\
\hline & Minimum temperature $\left({ }^{\circ} \mathrm{C}\right)$ & -22.6 & -13.0 & -11.8 \\
\hline & Average temperature $\left({ }^{\circ} \mathrm{C}\right)$ & 8.4 & 8.0 & 9.76 \\
\hline & Average temperature in the last 100 days $\left({ }^{\circ} \mathrm{C}\right)$ & 16.8 & 16.3 & 16.6 \\
\hline \multirow{6}{*}{ 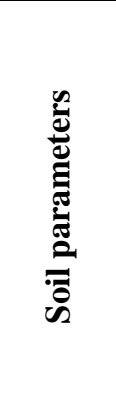 } & Soil type & \multicolumn{3}{|c|}{ Chernozem } \\
\hline & $\mathrm{pH}(\mathrm{KCl})$ & \multicolumn{3}{|c|}{7.25} \\
\hline & Humus (m/m \%) & \multicolumn{3}{|c|}{2.8} \\
\hline & $\mathrm{P}_{2} \mathrm{O}_{5}(\mathrm{mg} / \mathrm{kg})$ & \multicolumn{3}{|c|}{210} \\
\hline & $\mathrm{K}_{2} \mathrm{O}(\mathrm{mg} / \mathrm{kg})$ & \multicolumn{3}{|c|}{210} \\
\hline & $\begin{array}{l}\text { Yearly average } \mathrm{N} \text { input as } \\
\text { NPK combined fertilizer } \\
\text { (active ingredients, kg/ha) }\end{array}$ & \multicolumn{3}{|c|}{120} \\
\hline \multirow{3}{*}{ 范茪 } & Previous crop & Oilseed rape & Oilseed radish & Oilseed radish \\
\hline & Sowing density & \multicolumn{3}{|c|}{550 seeds $/ \mathrm{m}^{2}$} \\
\hline & Growing period (days) & 260 & 271 & 268 \\
\hline
\end{tabular}


Supplementary Table 2. Pairwise comparison of yields of high AX lines and control varieties

\begin{tabular}{|c|c|c|c|c|c|c|}
\hline \multirow[b]{2}{*}{ (I) Genotype } & \multirow[b]{2}{*}{ (J) Genotype } & \multirow[b]{2}{*}{ Mean difference (I-J) } & \multirow[b]{2}{*}{ Std. error } & \multirow[b]{2}{*}{ Sig. } & \multicolumn{2}{|c|}{ 95\% Confidence interval } \\
\hline & & & & & Lower Boundary & Upper Boundary \\
\hline \multirow[t]{14}{*}{ Mv-Nádor } & UK/YU_6 & 0.93833 & 0.33179 & 0.375 & -0.3186 & 2.1953 \\
\hline & UK/YU_7 & 0.87667 & 0.33179 & 0.494 & -0.3803 & 2.1336 \\
\hline & UK/YU_3 & 0.24167 & 0.33179 & 1.000 & -1.0153 & 1.4986 \\
\hline & UK/YU_4 & 0.31333 & 0.33179 & 1.000 & -0.9436 & 1.5703 \\
\hline & UK/YU_8 & 0.86167 & 0.33179 & 0.524 & -0.3953 & 2.1186 \\
\hline & LU/YU_11 & 0.63667 & 0.33179 & 0.914 & -0.6203 & 1.8936 \\
\hline & LU/YU_5 & 1.06000 & 0.33179 & 0.193 & -0.1969 & 2.3169 \\
\hline & LU/YU_7 & $1.95833^{*}$ & 0.33179 & 0.000 & 0.7014 & 3.2153 \\
\hline & LU/YU_10 & $1.98833^{*}$ & 0.33179 & 0.000 & 0.7314 & 3.2453 \\
\hline & LU/YU_8 & $1.78333^{*}$ & 0.33179 & 0.001 & 0.5264 & 3.0403 \\
\hline & LU/YU_4 & $1.51500^{*}$ & 0.33179 & 0.006 & 0.2581 & 2.7719 \\
\hline & MA/YU_1 & 0.19500 & 0.33179 & 1.000 & -1.0619 & 1.4519 \\
\hline & UK/YU_15 & 0.83167 & 0.33179 & 0.586 & -0.4253 & 2.0886 \\
\hline & LU/YU_6 & 0.60833 & 0.33179 & 0.941 & -0.6486 & 1.8653 \\
\hline \multirow[t]{14}{*}{ Mv-Lucilla } & UK/YU_6 & $1.33333^{*}$ & 0.33179 & 0.028 & 0.0764 & 2.5903 \\
\hline & UK/YU_7 & $1.27167^{\star}$ & 0.33179 & 0.045 & 0.0147 & 2.5286 \\
\hline & UK/YU_3 & 0.63667 & 0.33179 & 0.914 & -0.6203 & 1.8936 \\
\hline & UK/YU_4 & 0.70833 & 0.33179 & 0.820 & -0.5486 & 1.9653 \\
\hline & UK/YU_8 & 1.25667 & 0.33179 & 0.050 & -0.0003 & 2.5136 \\
\hline & LU/YU_11 & 1.03167 & 0.33179 & 0.228 & -0.2253 & 2.2886 \\
\hline & LU/YU_5 & $1.45500^{*}$ & 0.33179 & 0.010 & 0.1981 & 2.7119 \\
\hline & LU/YU_7 & $2.35333^{*}$ & 0.33179 & 0.000 & 1.0964 & 3.6103 \\
\hline & LU/YU_10 & $2.38333^{*}$ & 0.33179 & 0.000 & 1.1264 & 3.6403 \\
\hline & LU/YU_8 & $2.17833^{*}$ & 0.33179 & 0.000 & 0.9214 & 3.4353 \\
\hline & LU/YU_4 & $1.91000^{*}$ & 0.33179 & 0.000 & 0.6531 & 3.1669 \\
\hline & MA/YU_1 & 0.59000 & 0.33179 & 0.954 & -0.6669 & 1.8469 \\
\hline & UK/YU_15 & 1.22667 & 0.33179 & 0.063 & -0.0303 & 2.4836 \\
\hline & LU/YU_6 & 1.00333 & 0.33179 & 0.268 & -0.2536 & 2.2603 \\
\hline \multirow[t]{14}{*}{ Mulan } & UK/YU_6 & $1.30667^{*}$ & 0.33179 & 0.034 & 0.0497 & 2.5636 \\
\hline & UK/YU_7 & 1.24500 & 0.33179 & 0.055 & -0.0119 & 2.5019 \\
\hline & UK/YU_3 & 0.61000 & 0.33179 & 0.939 & -0.6469 & 1.8669 \\
\hline & UK/YU_4 & 0.68167 & 0.33179 & 0.860 & -0.5753 & 1.9386 \\
\hline & UK/YU_8 & 1.23000 & 0.33179 & 0.061 & -0.0269 & 2.4869 \\
\hline & LU/YU_11 & 1.00500 & 0.33179 & 0.266 & -0.2519 & 2.2619 \\
\hline & LU/YU_5 & $1.42833^{*}$ & 0.33179 & 0.013 & 0.1714 & 2.6853 \\
\hline & LU/YU_7 & $2.32667^{*}$ & 0.33179 & 0.000 & 1.0697 & 3.5836 \\
\hline & LU/YU_10 & $2.35667^{*}$ & 0.33179 & 0.000 & 1.0997 & 3.6136 \\
\hline & LU/YU_8 & $2.15167^{*}$ & 0.33179 & 0.000 & 0.8947 & 3.4086 \\
\hline & LU/YU_4 & $1.88333^{*}$ & 0.33179 & 0.000 & 0.6264 & 3.1403 \\
\hline & MA/YU_1 & 0.56333 & 0.33179 & 0.970 & -0.6936 & 1.8203 \\
\hline & UK/YU_15 & 1.20000 & 0.33179 & 0.076 & -0.0569 & 2.4569 \\
\hline & LU/YU_6 & 0.97667 & 0.33179 & 0.309 & -0.2803 & 2.2336 \\
\hline \multirow[t]{4}{*}{ Lupus } & UK/YU_6 & 0.21167 & 0.33179 & 1.000 & -1.0453 & 1.4686 \\
\hline & UK/YU_7 & 0.15000 & 0.33179 & 1.000 & -1.1069 & 1.4069 \\
\hline & UK/YU_3 & -0.48500 & 0.33179 & 0.993 & -1.7419 & 0.7719 \\
\hline & UK/YU_4 & -0.41333 & 0.33179 & 0.999 & -1.6703 & 0.8436 \\
\hline
\end{tabular}




\begin{tabular}{|c|c|c|c|c|c|c|}
\hline & UK/YU_8 & 0.13500 & 0.33179 & 1.000 & -1.1219 & 1.3919 \\
\hline & LU/YU_11 & -0.09000 & 0.33179 & 1.000 & -1.3469 & 1.1669 \\
\hline & LU/YU_5 & 0.33333 & 0.33179 & 1.000 & -0.9236 & 1.5903 \\
\hline & LU/YU_7 & 1.23167 & 0.33179 & 0.060 & -0.0253 & 2.4886 \\
\hline & LU/YU_10 & $1.26167^{*}$ & 0.33179 & 0.048 & 0.0047 & 2.5186 \\
\hline & LU/YU_8 & 1.05667 & 0.33179 & 0.197 & -0.2003 & 2.3136 \\
\hline & LU/YU_4 & 0.78833 & 0.33179 & 0.674 & -0.4686 & 2.0453 \\
\hline & MA/YU_1 & -0.53167 & 0.33179 & 0.983 & -1.7886 & 0.7253 \\
\hline & UK/YU_15 & 0.10500 & 0.33179 & 1.000 & -1.1519 & 1.3619 \\
\hline & LU/YU_6 & -0.11833 & 0.33179 & 1.000 & -1.3753 & 1.1386 \\
\hline \multirow[t]{14}{*}{ Yumai-34 } & UK/YU_6 & -0.86833 & 0.33179 & 0.511 & -2.1253 & 0.3886 \\
\hline & UK/YU_7 & -0.93000 & 0.33179 & 0.390 & -2.1869 & 0.3269 \\
\hline & UK/YU_3 & $-1.56500^{*}$ & 0.33179 & 0.004 & -2.8219 & -0.3081 \\
\hline & UK/YU_4 & $-1.49333^{*}$ & 0.33179 & 0.007 & -2.7503 & -0.2364 \\
\hline & UK/YU_8 & -0.94500 & 0.33179 & 0.363 & -2.2019 & 0.3119 \\
\hline & LU/YU_11 & -1.17000 & 0.33179 & 0.094 & -2.4269 & 0.0869 \\
\hline & LU/YU_5 & -0.74667 & 0.33179 & 0.754 & -2.0036 & 0.5103 \\
\hline & LU/YU_7 & 0.15167 & 0.33179 & 1.000 & -1.1053 & 1.4086 \\
\hline & LU/YU_10 & 0.18167 & 0.33179 & 1.000 & -1.0753 & 1.4386 \\
\hline & LU/YU_8 & -0.02333 & 0.33179 & 1.000 & -1.2803 & 1.2336 \\
\hline & LU/YU_4 & -0.29167 & 0.33179 & 1.000 & -1.5486 & 0.9653 \\
\hline & MA/YU_1 & $-1.61167^{\star}$ & 0.33179 & 0.003 & -2.8686 & -0.3547 \\
\hline & UK/YU_15 & -0.97500 & 0.33179 & 0.312 & -2.2319 & 0.2819 \\
\hline & LU/YU_6 & -1.19833 & 0.33179 & 0.077 & -2.4553 & 0.0586 \\
\hline \multirow[t]{14}{*}{ Ukrainka } & UK/YU_6 & 0.59167 & 0.33179 & 0.953 & -0.6653 & 1.8486 \\
\hline & UK/YU_7 & 0.53000 & 0.33179 & 0.983 & -0.7269 & 1.7869 \\
\hline & UK/YU_3 & -0.10500 & 0.33179 & 1.000 & -1.3619 & 1.1519 \\
\hline & UK/YU_4 & -0.03333 & 0.33179 & 1.000 & -1.2903 & 1.2236 \\
\hline & UK/YU_8 & 0.51500 & 0.33179 & 0.988 & -0.7419 & 1.7719 \\
\hline & LU/YU_11 & 0.29000 & 0.33179 & 1.000 & -0.9669 & 1.5469 \\
\hline & LU/YU_5 & 0.71333 & 0.33179 & 0.812 & -0.5436 & 1.9703 \\
\hline & LU/YU_7 & $1.61167^{*}$ & 0.33179 & 0.003 & 0.3547 & 2.8686 \\
\hline & LU/YU_10 & $1.64167^{\star}$ & 0.33179 & 0.002 & 0.3847 & 2.8986 \\
\hline & LU/YU_8 & $1.43667^{\star}$ & 0.33179 & 0.012 & 0.1797 & 2.6936 \\
\hline & LU/YU_4 & 1.16833 & 0.33179 & 0.095 & -0.0886 & 2.4253 \\
\hline & MA/YU_1 & -0.15167 & 0.33179 & 1.000 & -1.4086 & 1.1053 \\
\hline & UK/YU_15 & 0.48500 & 0.33179 & 0.993 & -0.7719 & 1.7419 \\
\hline & LU/YU_6 & 0.26167 & 0.33179 & 1.000 & -0.9953 & 1.5186 \\
\hline
\end{tabular}

* Mean difference is significant at $\mathrm{P}=0.05$

Varieties Mv-Nádor, Mv-Lucilla and Mulan were yield controls in recent national trials

Summary Table:

\begin{tabular}{|l|c|c|c|c|c|c|}
\hline & Mv-Nádor & Mv-Lucilla & Mulan & Lupus & Yumai-34 & Ukrainka \\
\hline UK/YU_6 & & $\star$ & $*$ & & & \\
\hline UK/YU_7 & & $*$ & & & & \\
\hline UK/YU_3 & & & & & $*$ & \\
\hline UK/YU_4 & & & & & & \\
\hline UK/YU_8 & & & & & & \\
\hline LU/YU_11 & & & & & & \\
\hline LU/YU_5 & & $*$ & $*$ & & & \\
\hline LU/YU_7 & $*$ & $*$ & $*$ & & & $*$ \\
\hline LU/YU_10 & $*$ & $*$ & $*$ & $*$ & & $*$ \\
\hline
\end{tabular}




\begin{tabular}{|l|l|l|l|l|l|l|}
\hline LU/YU_8 & $*$ & $*$ & $*$ & & & $*$ \\
\hline LU/YU_4 & $*$ & $*$ & $*$ & & & \\
\hline MA/YU_1 & & & & & $*$ & \\
\hline UK/YU_15 & & & & & & \\
\hline
\end{tabular}

*Yield was significantly different at $\mathrm{P}=0.05$ 
Table 1. Correlation of arabinoxylan content with physical, compositional and breadmaking properties of wheat breeding lines (2013-2015)

\begin{tabular}{|c|c|c|c|c|c|c|c|c|c|c|c|c|c|c|c|c|c|c|}
\hline & TOT-AX & WE-AX & $T W$ & TKW & Flour yield & Protein & Gluten & GI & Zeleny & DevTime & Stability & Softening & WA & $Q N$ & Starch & $S D^{+}$ & $\mathrm{HI}^{+}$ & Ash+ \\
\hline TOT-AX & 1 & & & & & & & & & & & & & & & & & \\
\hline WE-AX & $0.586 * * *$ & 1 & & & & & & & & & & & & & & & & \\
\hline TW & $-0.531^{* * *}$ & n.s. & 1 & & & & & & & & & & & & & & & \\
\hline TKW & n.s. & n.s. & n.s. & 1 & & & & & & & & & & & & & & \\
\hline $\begin{array}{l}\text { Flour } \\
\text { yield }\end{array}$ & $-0.456^{* *}$ & $-0.401^{*}$ & n.s. & $0.341^{*}$ & 1 & & & & & & & & & & & & & \\
\hline Protein & n.s. & n.s. & n.s. & n.s. & n.s. & 1 & & & & & & & & & & & & \\
\hline Gluten & $0.368 *$ & n.s. & n.s. & n.s. & n.s. & $0.931 * * *$ & 1 & & & & & & & & & & & \\
\hline GI & n.s. & n.s. & n.s. & $-0.654 * * *$ & n.s. & n.s. & n.s. & 1 & & & & & & & & & & \\
\hline Zeleny & n.s. & n.s. & n.s. & n.s. & n.s. & $0.588 * * *$ & $0.468^{* *}$ & n.s. & 1 & & & & & & & & & \\
\hline DevTime & n.s. & n.s. & n.s. & $-0.464 * *$ & n.s. & $0.502^{* *}$ & n.s. & $0.647^{* * *}$ & $0.409 *$ & 1 & & & & & & & & \\
\hline Stability & n.s. & n.s. & n.s. & $-0.355^{*}$ & n.s. & $\begin{array}{l}-0.379 * \\
\end{array}$ & $-0.476^{* *}$ & $0.437 * *$ & $-0.328^{*}$ & n.s. & 1 & & & & & & & \\
\hline Softening & n.s. & n.s. & n.s. & $0.523^{* * *}$ & n.s. & $-0.446^{* *}$ & n.s. & $-0.706 * * *$ & n.s. & $-0.857 * * *$ & n.s. & 1 & & & & & & \\
\hline WA & $0.486 * *$ & n.s. & n.s. & n.s. & n.s. & $0.846^{* * *}$ & $0.878^{* * *}$ & n.s. & $0.421 * *$ & $0.442 * *$ & $-0.428 * *$ & n.s. & 1 & & & & & \\
\hline QN & n.s. & n.s. & n.s. & $-0.504 * *$ & n.s. & $0.428^{* * *}$ & n.s. & $0.707^{* * *}$ & $0.329 *$ & $0.951^{* * *}$ & n.s. & $-0.941^{* * *}$ & $0.341 *$ & 1 & & & & \\
\hline Starch & $-0.537 * * *$ & n.s. & n.s & n.s. & n.s. & $-0.502^{* *}$ & $-0.527^{* * *}$ & n.s. & n.s. & n.s. & n.s. & n.s. & $-0.590^{* * *}$ & n.s. & 1 & & & \\
\hline SD+ & n.s. & $-0.503 * *$ & n.s. & n.s. & $-0.635^{* * *}$ & n.s. & n.s. & n.s. & n.s. & n.s. & n.s. & n.s. & n.s. & n.s. & n.s. & 1 & & \\
\hline $\mathrm{HI}+$ & n.s. & n.s. & n.s. & n.s. & $-0.690 * * *$ & $0.363^{*}$ & $0.398^{*}$ & n.s. & n.s. & n.s. & n.s. & n.s. & $0.621 * * *$ & n.s. & n.s. & $0.485^{* *}$ & 1 & \\
\hline Ash+ & n.s. & n.s. & -0.337* & n.s. & $-0.522^{* * *}$ & n.s. & n.s. & n.s. & n.s. & n.s. & n.s. & n.s. & $0.367^{*}$ & n.s. & $-0.440 * *$ & n.s. & n.s. & 1 \\
\hline $\begin{array}{l}\text { Grain } \\
\text { vield }\end{array}$ & n.s. & n.s. & n.s. & n.s. & $0.613^{*}$ & $-0.626^{* *}$ & $-0.609 *$ & n.s. & n.s. & n.s. & n.s. & n.s. & $-0.560^{*}$ & n.s. & $0.434 * *$ & n.s. & n.s. & n.s. \\
\hline
\end{tabular}

$\mathrm{r}_{5 \%}=0.3246^{*}, \mathrm{r}_{1 \%}=0.4182^{* *}, \mathrm{r}_{0.1 \%}=0.5189, \mathrm{n}=35$, n.s.- not significant, AX- arabinoxylan, DevTime- dough development time, GI- gluten index, HI- hardness index, QN-

Hungarian Farinograph quality number, SD- starch damage, Softening- Farinograph dough softening, Stability- Farinograph dough stability, TOT- total, TKW- thousand-

kernel weight, TW- test weight, WA- Farinograph flour water absorption, WE- water-extractable, Zeleny- Zeleny sedimentation.

+ data from 2015, 35 samples, where $\mathrm{r}_{5 \%}=0.3246^{*}, \mathrm{r}_{1 \%}=0.4182 * *, \mathrm{r}_{0.1 \%}=0.5189, \mathrm{n}=351$

$\$$ data from 2015, 14 samples, where $\mathrm{r}_{5 \%}=0.4973 *, \mathrm{r}_{1 \%}=0.6226^{* *}, \mathrm{r}_{0.1 \%}=0.7420, \mathrm{n}=14$ 